This item was submitted to Loughborough's Institutional Repository (https://dspace.lboro.ac.uk/) by the author and is made available under the following Creative Commons Licence conditions.

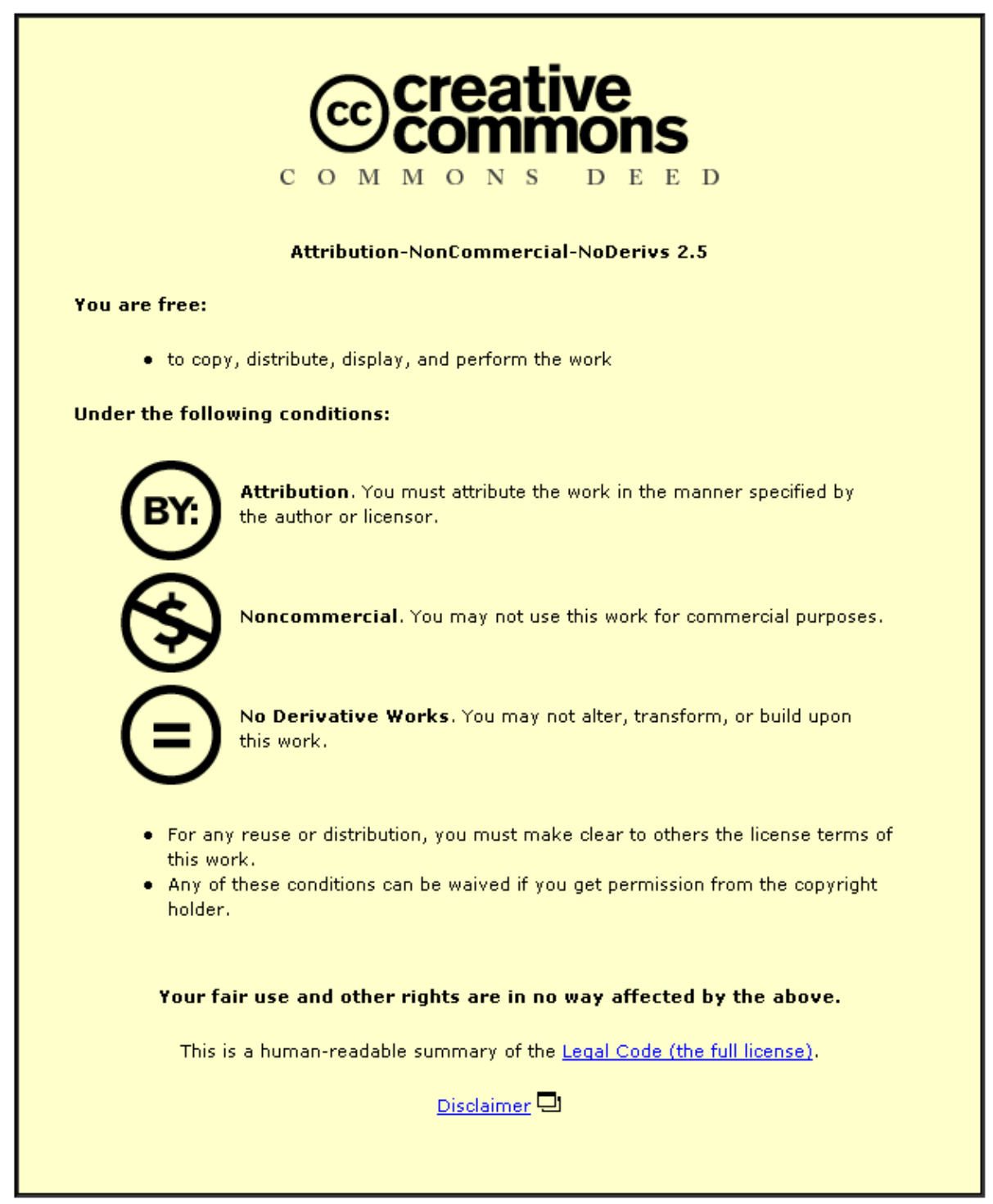

For the full text of this licence, please go to: http://creativecommons.org/licenses/by-nc-nd/2.5/ 


\section{Integrated system for temperature-controlled fast protein liquid chromatography comprising improved copolymer modified beaded agarose adsorbents and a travelling cooling zone reactor arrangement}

Tobias K.H. Müller ${ }^{\mathrm{a}, \#, \text {, Ping Cao }}{ }^{\mathrm{b},}$, Stephanie Ewert ${ }^{\mathrm{a}, \mathrm{b}}$, Jonas Wohlgemuth ${ }^{\mathrm{a}}$, Haiyang Liu ${ }^{\mathrm{b}, \dagger}$, Thomas C. Willett ${ }^{\mathrm{b}}$, Eirini Theodosiou ${ }^{\mathrm{b},}$, Owen R.T. Thomas, ${ }^{\mathrm{b},{ }^{*}}$, Matthias Franzreb $^{\mathrm{a},{ }^{, * *}}$

${ }^{a}$ Institute for Functional Interfaces, Karlsruhe Institute of Technology, Hermann-vonHelmholtz-Platz 1, 76344 Eggenstein-Leopoldshafen, Germany

${ }^{\mathrm{b}}$ School of Chemical Engineering, College of Engineering and Physical Sciences, University of Birmingham, Edgbaston, Birmingham B15 2TT, England, UK

\#Present address: Evonik Industries AG, Rodenbacher Chaussee 4, 63457 Hanau, Germany

${ }^{\dagger}$ Present address: GenScript Corporation (Nanjing) Co. Ltd, NanJing 211100, China

Fresent address: Department of Chemical Engineering, School of Aeronautical, Automotive, Chemical and Materials Engineering, Loughborough University, Loughborough, LE11 3TU, England, UK

*Corresponding author. Tel.: +44 121 4145278; fax +44 1214145377

**Corresponding author. Tel.: +49 721608 23595; fax: +49 72160823478

E-mail addresses: $\underline{\text { o.r.t.thomas@ @ham.ac.uk (O.R.T. Thomas); matthias.franzreb@ kit.edu }}$

(M. Franzreb)

${ }^{\S}$ These authors contributed equally to the experimental work in this study 


\section{Abstract}

An integrated approach to temperature-controlled chromatography, involving copolymer modified agarose adsorbents and a novel travelling cooling zone reactor (TCZR) arrangement, is described. Sepharose CL6B was transformed into a thermoresponsive cation exchange adsorbent (thermoCEX) in four synthetic steps: (i) epichlorohydrin activation; (ii) amine capping; (iii) 4,4'-azobis(4-cyanovaleric acid) immobilization; and 'graft from' polymerization of poly( $\mathrm{N}$-isopropylacrylamide-co- $\mathrm{N}$-tert-butylacrylamide-co-acrylic acid-co$N, N^{\prime}$-methylenebisacrylamide). FT-IR, ${ }^{1} \mathrm{H}$ NMR, gravimetry and chemical assays allowed precise determination of the adsorbent's copolymer composition and loading, and identified the initial epoxy activation step as a critical determinant of 'on-support' copolymer loading, and in turn, protein binding performance. In batch binding studies with lactoferrin, thermoCEX's binding affinity and maximum adsorption capacity rose smoothly with temperature increase from 20 to $50^{\circ} \mathrm{C}$. In temperature shifting chromatography experiments employing thermoCEX in thermally-jacketed columns, $44-51 \%$ of the lactoferrin adsorbed at $42{ }^{\circ} \mathrm{C}$ could be desorbed under binding conditions by cooling the column to $22{ }^{\circ} \mathrm{C}$, but the elution peaks exhibited strong tailing. To more fully exploit the potential of thermoresponsive chromatography adsorbents, a new column arrangement, the TCZR, was developed. In TCZR chromatography, a narrow discrete cooling zone (special assembly of copper blocks and Peltier elements) is moved along a bespoke fixed-bed separation columnfilled with stationary phase. In tests with thermoCEX, it was possible to recover $65 \%$ of the lactoferrin bound at 35 ${ }^{\circ} \mathrm{C}$ using 8 successive movements of the cooling zone at a velocity of $0.1 \mathrm{~mm} / \mathrm{s}$; over half of the recovered protein was eluted in the first peak in more concentrated form than in the feed. Intra-particle diffusion of desorbed protein out of the support pores, and the ratio between the velocities of the cooling zone and mobile phase were identified as the main parameters affecting TCZR performance. In contrast to conventional systems, which rely on cooling the 
whole column to effect elution and permit only batch-wise operation, TCZR chromatography generates sharp concentrated elution peaks without tailing effects and appears ideally suited for continuous operation.

Keywords: Bioseparation; Ion exchange adsorption; Lactoferrin; Lower critical solution temperature (LCST); $N$-isopropylacrylamide; Smart polymers

\section{Introduction}

Bioprocess chromatography suffers from several problems that compromise its sustainability. Current 'adsorption - desorption' processes are expensive, suffer from low productivity (given that most involve batch-wise operation in fixed beds), and employ large volumes of buffer for equilibrating, washing, eluting and cleaning of columns, generating as a consequence excessive quantities of waste [1-3]. Effective solutions to these significant problems have not yet been forthcoming, but would clearly make for much leaner, greener and more sustainable manufacturing of valuable bio-commodities [3].

In this context, we introduce an integrated bioseparation concept, which makes use of discrete 'local' changes in temperature to control adsorption - desorption equilibria, and relies on the combined use of chromatographic supports modified with a methylene bisacrylamide (MBAAm) cross-linked 'smart' temperature-sensitive anionic copolymer, i.e. $\operatorname{poly}(\mathrm{N}$-isopropylacrylamide-co- $\mathrm{N}$-tert-butylacrylamide-co-acrylic acid) (abbreviated to pNIPAAm-co-tBAAm-co-AAc), and a novel device that permits continuous thermally mediated bioseparation.

Smart temperature-sensitive or thermoresponsive polymers are polymers that exhibit inverse temperature solubility behaviour, i.e. they are water-soluble at low temperature, and 
insoluble at high temperature above a critical temperature known as the lower critical solution temperature (LCST) [4]. They have been shown as potentially useful in diverse biomedical and biotechnological applications [3,5-7]. By far the most studied species is pNIPAAm [8-10]. pNIPAAm undergoes an abrupt reversible 'hydrophilic coil - hydrophobic globule' phase transition in water at an LCST of $32-34^{\circ} \mathrm{C}[8,9]$, and importantly its LCST is relatively insensitive to variation in $\mathrm{pH}$, concentration or chemical environment $[9,10]$.

A significant body of work on the modification of chromatographic packing materials with thermoresponsive polymers (mostly pNIPAAm or pNIPAAm based copolymers) has appeared since the first reports in the early-mid 1990s [11-13]. Most of this has concentrated on exploiting the principle of thermally induced extension and collapse of polymer chains for modulating the fractionation range in size exclusion chromatography $[11,12,14]$, hydrophobicity in HPLC [13,15-18], and balancing electrostatic and hydrophobic interactions in ion exchange chromatography, through the use of copolymers containing both thermoresponsive and ion exchange components [19-25], rather than mitigating ligand masking and 'forced elution' in pseudoaffinity chromatography $[3,26]$. To this day, the vast body of work on thermoresponsive chromatography pertains to the modification and subsequent use of small pored inorganic (glass, silica) or hydrophobic (polystyrene based) chromatography supports in analytical HPLC separations of small biomolecules (especially steroids). By contrast, applications involving soft macroporous supports, appropriate for bioprocess scale separations of large macromolecular targets (globular proteins, nucleic acids, viruses), have received very little attention thus far. In some respects this is surprising, given that the use of temperature responsive chromatography materials offers cost-effective environmentally friendly solutions to the isolation of commercially valuable biocomponents from biopharma, bioindustry, agricultural, food and other complex process streams [3,24]. Though not discussed in the literature, one of the main reasons for this is likely to be 
difficulties in scaling up thermo-responsive chromatography with such media and column formats, and further, that macromolecules tend to be much more thermally labile than their smaller counterparts. On the latter point, Maharjan and coworkers [24] highlighted the attraction of this type of chromatography for the separation of thermally robust targets, such as lactoferrin (LF) from ultra-high volumes of bovine whey feedstocks. Using methods originally applied to silica matrices, these authors were the first to prepare thermoresponsive cation exchange adsorbents (modified with lightly cross-linked pNIPAAm-co-tBAAm-coAAc) from cross-linked beaded agarose supports. In the same report the authors subsequently demonstrated both temperature dependent adsorption of LF and thermally mediated elution of the adsorbed protein in batch and dynamic column experiments; the latter being conducted by tempering the whole column in a water bath.

In this paper, we extend upon Maharjan and coworkers [3,24] work by integrating the use of thermoresponsive cation exchangers (hereafter referred to as thermoCEX) with a new column arrangement specifically tailored for thermoresponsive chromatography. Our solution is, rather than subject the whole column to temperature changes in a water bath or via a surrounding jacket, we subject only a small part of it via a computer controlled motor-driven travelling Peltier block arrangement. In this study involving inverse temperature responsive copolymer modified adsorbents, where elution is observed on cooling, we term the set up a travelling cooling zone reactor (TCZR). Note, in the opposite case, i.e. where the modifying polymer exhibits normal temperature solubility behaviour and/or elution occurs on heating, a travelling heating zone reactor (THZR) would be appropriate.

We first describe the preparation, characterization and comparison of thermoCEX adsorbents prepared for this study with those reported by Maharjan et al. [24]. Subsequently, we compare their chromatographic behaviour in the TCZR (under batch-wise operation) with that in a jacketed column, and further, identify the main parameters affecting the TCZR's 
performance, as intra-particle diffusion of desorbed protein out of the pores of the support, and the ratio between the velocities of the cooling zone and mobile phase. Finally, we address the steps that will be required to make preparative TCZR chromatography, and temperaturecontrolled adsorption-desorption chromatography in general, attractive propositions for the future.

\section{Experimental}

\subsection{Materials}

Bovine whey lactoferrin (MLF-1, 97\%) was received as a gift from Milei GmbH (Leutkirch, Germany). Sepharose CL-6B was obtained from GE Healthcare Life Sciences (Little Chalfont, Bucks, UK). The chemicals, $N$-isopropylacrylamide (97\%; NIPAAm), N-tertbutylacrylamide (97\%; $t$-BAAm), acrylic acid (anhydrous, 99\%, AAc), 2-ethoxy-1ethoxycarbonyl-1,2-dihydroquinoline ( $\geq 99 \%$; EEDQ), 4,4'-azobis(4-cyanovaleric acid) $(\geq 98 \% ; \quad \mathrm{ACV}), \quad N, N$-dimethylformamide $(>99.9 \% ; \quad \mathrm{DMF}), \quad N, N^{\prime}$-methylenebisacrylamide (99\%; MBAAm), epichlorohydrin (99\%; ECH), tetrahydrofuran (>99\%; THF), diethyl ether (>99.9\%), sodium borohydride (>99\%) and sodium hydroxide (anhydrous, $>98 \%$ ) were purchased from the Sigma-Aldrich Company Ltd (Poole, Dorset, UK), whereas absolute ethanol $(99.8+\%)$ and ammonia solution (AR grade, 0.88 S.G., 35\%) were acquired from Fisher Scientific UK Ltd (Loughborough, Leics, UK), di-sodium hydrogen phosphate (dihydrate, $\geq 99.5 \%$ ) was from Carl Roth $\mathrm{GmbH}+\mathrm{Co}$. KG (Karlsruhe, Germany), and bottled oxygen-free nitrogen gas was supplied by the British Oxygen Co Ltd (Windlesham, Surrey, UK). 


\subsection{Preparation of thermoresponsive cation exchange (thermoCEX) chromatography adsorbents}

The methods used to convert underivatized Sepharose CL-6B supports into thermoresponsive cation exchange matrices (thermoCEX) involve four successive steps - epoxide activation, amine capping, initiator immobilization and 'graft from' polymerization. These are detailed below and summarized schematically in Fig. 1.

\subsubsection{Epoxy activation [27]}

Washed suction-drained supports $(50 \mathrm{~g}, 71 \mathrm{ml})$ were mixed with $85 \mathrm{ml}$ of water in $250 \mathrm{ml}$ Pyrex ${ }^{\circledR}$ conical flasks and $40 \mathrm{ml}$ of $2 \mathrm{M} \mathrm{NaOH}$ before placing in a $40{ }^{\circ} \mathrm{C}$ shaking water bath (Julabo SW22, Labortechnik GmbH, Seelbach, Germany) reciprocating at $150 \mathrm{rpm}$ for $0.5 \mathrm{~h}$. Ten millilitres of ECH (99\%) was then added to a final concentration of $\sim 5 \%(\mathrm{v} / \mathrm{v})$, and reaction was allowed to proceed at $40{ }^{\circ} \mathrm{C}$ with shaking for an additional $2 \mathrm{~h}$. The resulting epoxy-activated supports were washed copiously with water under vacuum.

\subsubsection{Amine capping}

After washing, the oxirane groups of epoxy-activated Sepharose CL-6B were reacted and capped with ammonium ions using a procedure adapted from Hermansson et al. [28]. The supports $(47.5 \mathrm{~g}, 65 \mathrm{ml})$ were resuspended as a $\sim 57 \%(\mathrm{v} / \mathrm{v})$ slurry with $50 \mathrm{ml}$ of $2 \mathrm{M}$ ammonium hydroxide. After incubating overnight $(\sim 20 \mathrm{~h})$ at $\sim 30^{\circ} \mathrm{C}$ with shaking at $150 \mathrm{rpm}$, the amine-terminated supports were recovered, washed exhaustively at room temperature with water in a sintered glass filter under vacuum, and then stored in $20 \%$ (v/v) ethanol at 4 ${ }^{\circ} \mathrm{C}$ until required.

\subsubsection{Initiator immobilization}


The radical initiator ACV was coupled to amine-terminated Sepharose CL-6B using a modified version of Maharjan and co-workers' procedure [24], one adapted from methods originally applied to aminated silica matrices [15,16,21,22], employing EEDQ as the condensing agent. Amine-terminated supports were washed sequentially with 5 volumes each of $50 \%, 75 \%$ and $100 \%(\mathrm{v} / \mathrm{v})$ ethanol. For each wash, the supports were mixed 'endover-end' (0.25 h, RT, 35 rpm) on a Stuart Scientific SB1 tube rotator (Bibby Scientific Ltd, Stone, Staffs, UK), before recovering by vacuum filtration and resuspending in the next wash solution in the series. Subsequently, the drained supports $(45 \mathrm{~g}, 56 \mathrm{ml})$ were resuspended with $145 \mathrm{ml}$ of DMF containing $75 \mathrm{mM} \mathrm{ACV}$ and $150 \mathrm{mM}$ EEDQ. While housed in a zipper-locked inflatable glove box (AtmosBag, Sigma-Aldrich, UK), nitrogen gas was bubbled through the support slurries, before tightly sealing the reaction flasks with SubaSeal ${ }^{\circledR}$ rubber stoppers (Sigma-Aldrich, UK) and transferring to a shaking (150 rpm) water bath for $6 \mathrm{~h}$ of reaction at $\sim 25^{\circ} \mathrm{C}$. The ACV coupled matrices were recovered from reaction solvent by vacuum filtration and then washed by end-over-end mixing $(0.33 \mathrm{~h}, \mathrm{RT})$ and recovered by vacuum filtration, first with 5 volumes of DMF and subsequently with 5 volumes of absolute ethanol.

\subsubsection{Graft from polymerization of poly(NIPAAm-co-tBAAm-co-AAc-co-MBAAm) on ACV-} linked Sepharose CL-6B

The surfaces of ACV-Sepharose CL-6B were grafted with an immobilized lightly crosslinked (i.e. MBAAm as $1 \%$ of the total monomers) copolymer network of poly(NIPAAm-cotBAAm-co-AAc-co-MBAAm) using optimal monomer ratios identified by Maharjan et al. [24]. The method employed in this work was essentially that described by these authors, with minor modifications to pre and post washing regimes and reaction conditions. Suction-dried ACV-linked Sepharose CL-6B (25 g, $35 \mathrm{ml})$ was sequentially washed with $125 \mathrm{ml}$ aliquots of 
$20 \%, 50 \%, 75 \%$ and $100 \%(\mathrm{v} / \mathrm{v})$ ethanol in cycles of resuspension, 'end-over-end' mixing (0.33 h, RT, $20 \mathrm{rpm})$ and vacuum filtration. Subsequently, the supports were resuspended with $125 \mathrm{ml}$ of ethanol containing the dissolved monomers NIPAAm (900 mM), tBAAm (50 $\mathrm{mM})$ and AAc $(50 \mathrm{mM})$, and the cross-linking monomer MBAAm (10 $\mathrm{mM})$, before transferring to the environment of a glove box and bubbling nitrogen gas through the reaction slurries. After $0.5 \mathrm{~h}$ the reaction flasks were tightly stoppered, and placed in a shaking water bath operated at $150 \mathrm{rpm}$ and $80{ }^{\circ} \mathrm{C}$ for $16 \mathrm{~h}$. The reaction mixtures were cooled to room temperature and the poly(NIPAAm-co-tBAAm-co-AAc-co-MBAAm) grafted supports were recovered by vacuum filtration, before successively cycling through a descending ethanol concentration wash series $(100 \%, 75 \%, 50 \%, 20 \% \mathrm{v} / \mathrm{v})$ and then with water. Each cycle involved mixing the support with 5 volumes of the appropriate solvent $(0.33 \mathrm{~h}, \mathrm{RT}, 20 \mathrm{rpm})$, followed by vacuum filtration. After the final wash, the polymer grafted supports were resuspended with $20 \%(\mathrm{v} / \mathrm{v})$ ethanol and stored at $4{ }^{\circ} \mathrm{C}$ until required. The washes were retained for subsequent analysis (see 2.7 Analysis).

\subsection{Batch adsorption experiments}

For batch binding tests, pure LF solution of defined concentrations $\left(\mathrm{c}_{0}=1-40 \mathrm{mg} / \mathrm{ml}\right)$ were prepared in $10 \mathrm{mM}$ sodium phosphate $\mathrm{pH}$ 6.5. Aliquots $(0.9 \mathrm{ml})$ of these LF solutions were added to $0.1 \mathrm{ml}$ volumes of settled thermoCEX support before mixing at various temperatures between 20 and $50{ }^{\circ} \mathrm{C}$, for $1 \mathrm{~h}$ with shaking (1000 rpm, Thermomixer Comfort shaker, Eppendorf, Hamburg, Germany). After an additional $0.5 \mathrm{~h}$ at the selected incubation temperature without shaking, the supernatants were analyzed for residual protein content (see 2.7 Analysis). The protein bound to the supports was determined from the difference between the protein concentration in the starting binding solution and the supernatant after binding, and where appropriate the data was fitted to the Langmuir equation (Eq. 1): 
$q^{*}=\left(q_{\max } c^{*}\right) /\left(K_{d}+c^{*}\right)$

where $\mathrm{q}^{*}$ and $\mathrm{c}^{*}$ represent the equilibrium concentrations of adsorbed and liquid-phase protein respectively; $\mathrm{q}_{\max }$ is the maximum protein binding capacity of the support; and $\mathrm{K}_{\mathrm{d}}$ is the dissociation constant. Data was fitted to the model using the $\chi^{2}$ minimization procedure of SigmaPlot software version 10.0 (Systat Software Inc, CA, USA).

\subsection{Thermoresponsive CEX chromatography of LF in jacketed columns}

Fixed-beds $(4.3-4.7 \mathrm{ml})$ of thermoCEX matrix contained in glass $\mathrm{C} 10 / 20$ columns (internal diameter $=10 \mathrm{~mm}$, length $=20 \mathrm{~cm}$ ) equipped with JC 10/20 water jackets (GE Healthcare, Uppsala, Sweden) were initially employed for thermoresponsive CEX chromatography of LF. The column was connected to an Äkta Explorer 100 Air chromatography workstation (GE Healthcare, Uppsala, Sweden). The temperature within the column was adjusted via the column's water jacket by continuously circulating water through it from a 42 or $22{ }^{\circ} \mathrm{C}$ water bath and also by immersing the mobile phase reservoirs employed within the same water baths. Mobile phase entered the column from the buffer reservoirs via a spirally wound hollow stainless steel tube. Temperature switching was done manually, and experiments were performed in the following way. Columns were: (i) equilibrated with $10 \mathrm{mM}$ sodium phosphate buffer, pH $6.5(7.3-10.2 \mathrm{CV})$ at either 22 or $42{ }^{\circ} \mathrm{C}$, (ii) saturated with LF (supplied as a $14 \mathrm{mg} / \mathrm{ml}$ suspension in equilibration buffer; $5.0-8.8 \mathrm{CV}$ ) at the same temperature; (iii) washed with equilibration buffer $(13.6-15.7 \mathrm{CV})$ maintained at loading temperature; then (iv) subjected to either single or multiple temperature transitions (without change in the mobile phase composition); before finally (v) eluting residually bound LF at 22 ${ }^{\circ} \mathrm{C}$ using $1 \mathrm{M} \mathrm{NaCl}$ in $10 \mathrm{mM}$ sodium phosphate buffer, pH $6.5(9-13.2 \mathrm{CV})$. A mobile phase velocity (u) of $300 \mathrm{~cm} / \mathrm{h}$ was employed throughout. 


\subsection{Travelling Cooling Zone Reactor (TCZR)}

\subsubsection{Design of the TCZR}

The novel reactor device employed in this study (Fig. 2) comprises two main parts, namely (i) a bespoke fixed-bed column filled with a thermoresponsive stationary phase, and fabricated from stainless steel to ensure good heat conductance through the reactor wall; and (ii) a movable assembly of copper blocks and Peltier elements surrounding a small discrete zone of the separation column. The central part of this assembly can be cooled through adjustments to the Peltier elements, and the whole unit can be moved vertically up or down along the separation column, so that adsorbed protein in the cooling zone's region desorbs in response to a localized reduction in the column's temperature and consequent weakening of the bound species affinity for the thermoresponsive chromatography matrix. The temperatures of the column and movable assembly are measured and controlled with Pt 100 thermocouples linked to LabView Software (National Instruments, Austin, TX, USA), and motion of the copper block-Peltier assembly is accomplished via a ball bearing guided linear motorized axis capable of a minimum constant movement of $0.1 \mathrm{~mm} / \mathrm{s}$ (Festo AG, Munich, Germany) controlled by Festo's dedicated PC based software package (FCT - Festo Configuration Tool). The 'sandwich-like' construction of the travelling cooling zone assembly (depicted in Fig. 2b) consisting of three copper blocks and two Peltier elements (Type TB-109-1,4-1,5CH, Kryotherm, St. Petersburg, Russia), generating axial heat transfer from the $18 \mathrm{~mm}$ thick central cooling block to the $3 \mathrm{~mm}$ thick top and bottom copper blocks. The Peltier elements, sandwiched between the top and middle, and middle and bottom copper blocks, are operated by a MTTC-1410 controller (Laird Technologies, Chesterfield, MO, USA). To ensure maximal and homogeneous radial heat transfer, the thickness of the separation column's steel wall is just $1 \mathrm{~mm}$. The inner diameter and length of the separation column are $6 \mathrm{~mm}$ and $10 \mathrm{~cm}$ respectively, and the internal volume is $2.83 \mathrm{ml}$. 


\subsubsection{Theoretical considerations}

Figure 3 depicts theoretical concentration and loading profiles of a single adsorbed protein species, during the course of one complete movement of the travelling cooling zone along the full length of the separation column. For simplicity, a temperature-mediated 'all or nothing' affinity of the protein to the thermoresponsive solid phase is assumed, i.e. full binding at the elevated temperature and no binding at the reduced temperature in the cooling zone. During batch-wise operation of the TCZR a defined volume of protein solution is initially fed to the column, whilst the TCZR is switched off or parked at a position distant from the matrix filled part of the column. At the elevated temperature, complete adsorption of the protein adsorbate on the column is assumed. Immediately on completion of protein loading, binding buffer is applied as the mobile phase (Fig. 3, left). The middle section of Figure 3 shows the situation after the cooling zone has begun to move. Within the cooling zone, protein desorbs from the matrix into the interstitial liquid phase and is pumped through the column. Should any desorbed protein molecules move beyond the travelling cooling zone's influence, they will, given the elevated column temperature elsewhere, rebind to the matrix. As the cooling zone continues to travel along the column's length, it follows that the protein concentration in the small volume of interstitial mobile phase surrounded by the cooling assembly will increase, and thus a sharp elution peak result is expected (Fig. 3, right).

\subsection{Thermoresponsive CEX chromatography of LF in the TCZR}

The first test conducted with the TCZR described above (2.4) was performed using a constant surrounding temperature, $\Phi_{\mathrm{u}}$, of $35^{\circ} \mathrm{C}$, and the lowest possible axial velocity of the cooling zone $\left(\mathrm{v}_{\mathrm{c}}\right)$ of $0.1 \mathrm{~mm} / \mathrm{s}$, which generates a maximum temperature difference of $22.6{ }^{\circ} \mathrm{C}$ (i.e. during the cooling zone's progress along the column, parts of the column immediately 
adjacent to the centre of the cooling assembly were temporarily cooled down to $12.4^{\circ} \mathrm{C}$ ). The separation column (volume $=2.83 \mathrm{ml}$ ) was packed with thermoCEX Sepharose CL-6B matrix (packing factor $=1.2$ ) and $\mathrm{u}$ was maintained at $212 \mathrm{~cm} / \mathrm{h}$. Using the calculated bed voidage $(\varepsilon)$ of 0.31 , the interstitial velocity $\left(u_{i}\right)$ at this mobile phase velocity was determined as $682 \mathrm{~cm} / \mathrm{h}$. After initial equilibration of the column with $2 \mathrm{CV}$ of $10 \mathrm{mM}$ sodium phosphate buffer, $\mathrm{pH} 6.5,27 \mathrm{CV}$ of a $2 \mathrm{mg} / \mathrm{ml}$ suspension of LF (made up in the equilibration buffer) were applied to the column, before washing with a further $5 \mathrm{CV}$ of the same buffer. Thereafter, the cooling zone assembly was moved along the entire column length eight successive times at $\mathrm{v}_{\mathrm{c}}=0.1 \mathrm{~mm} / \mathrm{s}$, before finally eluting residually bound LF with $5 \mathrm{CV}$ of 10 mM sodium phosphate, $\mathrm{pH} 6.5$, supplemented with $1 \mathrm{M} \mathrm{NaCl}$.

In the second test, the separation column was equilibrated, loaded with LF and washed exactly as described for the first test. Thereafter however, the cooling zone was moved along the whole column six times at different speeds (i.e. at $1.9 \mathrm{~mm} / \mathrm{s}$ for the first movement, $1.0 \mathrm{~mm} / \mathrm{s}$ for the second, and at $0.1 \mathrm{~mm} / \mathrm{s}$ for the remaining movements, $3-6$ inclusive), before once again desorbing residually bound LF with a $1 \mathrm{M} \mathrm{NaCl}$ step gradient. In these experiments, the different cooling zone velocities employed of $1.9,1.0$ and $0.1 \mathrm{~mm} / \mathrm{s}$ resulted in maximum temperature differences of $\sim 9,12.5$ and $22.6^{\circ} \mathrm{C}$, respectively.

Fractions generated during the above experiments were subsequently analysed offline for protein content (see 2.7 Analysis).

\subsection{Analysis}

The reactive epoxide group content introduced into Sepharose CL-6B following activation with epichlorohydrin was determined exactly as described by Sundberg and Porath [29], employing the ring opening reaction of oxiranes with sodium thiosulphate. This reaction 
results in the release of $\mathrm{OH}^{-}$, which is followed by titration with $\mathrm{HCl}$. The support's epoxide density was determined from the amount of $\mathrm{HCl}$ required to maintain neutrality.

FT-IR analysis was employed in two ways, i.e. qualitatively for direct detection of chemical changes introduced into Sepharose CL-6B at various stages during the creation of thermoCEX supports, and quantitatively on liquid samples, in order to determine consumption of 'NIPAAm + tBAAm' monomers, and thereby quantify the amount of 'NIPAAm + tBAAm' installed on thermoCEX supports. For solid samples, aliquots of aqueous particle suspension were pipetted onto watchglasses and dried in an oven $\left(60^{\circ} \mathrm{C}, 20\right.$ h). Small quantities $(\sim 3 \mathrm{mg})$ of dried support samples were then blended with $300 \mathrm{mg}$ of potassium bromide by grinding in agate mortar, until a fine, homogenous powder was produced, before pressing the mixtures into a $13 \mathrm{~mm}$ die using a 15 ton Atlas manual hydraulic press (Model GS15011, Specac Ltd, Orpington, Kent, UK), producing FT-IR suitable tablets. FT-IR spectra of each tablet were recorded using a Nicolet 380 FT-IR (Nicolet 380, Thermo Fischer Scientific, Waltham, MA, USA) in direct beam mode. Sixtyfour scans were averaged to yield spectra at a resolution of $2 \mathrm{~cm}^{-1}$. Attenuated Total Reflectance FT-IR (ATR FT-IR) was employed for estimation of 'NIPAAm + tBAAm' in liquid samples. Routinely, $150 \mu \mathrm{l}$ of each solution was applied to the surface of the Smart 53 Orbit diamond accessory of the Nicolet 380 FT-IR, and scanned 64 times at a resolution of 2 $\mathrm{cm}^{-1}$ in Attenuated Total Reflection mode. A measurement without any sample in the beam was used as background to keep a relative scale for the adsorption intensity. Background measurements were taken every $0.5 \mathrm{~h}$ during sample measurements. NIPAAm, tBAAm and MBAAm give two characteristic peaks in FT-IR, i.e. one at $\sim 1550 \mathrm{~cm}^{-1}$ corresponding to N$\mathrm{H}$ bending and another for amide $\mathrm{C}=\mathrm{O}$ stretching at $1670 \mathrm{~cm}^{-1}$, which is also present in spectra of the AAc monomer. The former N-H bending peak was therefore employed for determination of 'NIPAAm + tBAAm + MBAAm'. The ATR spectrum of standards, i.e. 
various dilutions of the initial monomer mixture NIPAAm: tBAAm: AAc: MBAAm (employed in a ratio of 90:5:5:1), were obtained by subtracting the spectrum of pure water from the aqueous solutions spectra. The Version 7.3 OMNIC TM DS (Data Security) software (Thermo Fischer Scientific, Waltham, MA, USA), was used as the interface for data collection and processing (interpretations of interferograms and peak area measurements). The area under the N-H bending peak of each spectrum was calculated, keeping the same region and baseline at $1575-1500 \mathrm{~cm}^{-1}$ during all the readings, and the combined concentration of 'NIPAAm + tBAAm + MBAAm' in samples was estimated by reference to standard curves $\left(\mathrm{R}^{2}>0.98\right)$. The small contribution to this signal from the cross-linking monomer, MBAAm, which accounted for $0.99 \%$ of the total monomer concentration and $2.03 \%$ of the N-H bending peak amide, was subtracted to give a value for 'NIPAAm + tBAAm'.

Gravimetric analysis was routinely performed on solid supports and on dried residues arising from liquid samples, obtained throughout the different stages of thermoCEX synthesis, and was used to allow determination of support immobilised ACV and copolymer contents, as well as the amount of free copolymer and unreacted monomers in solution at the end of the polymerization reaction following their separation from one another (detailed below). For solid support measurements, approximately $1 \mathrm{~g}$ quantities of suction-drained support samples were accurately weighed in pre-weighed glass crucibles before drying to constant weight in a $60{ }^{\circ} \mathrm{C}$ oven $(\sim 20 \mathrm{~h})$, weighing, cooling to room temperature in a dessiccator jar and weighing accurately on an analytical balance. One gram suction-drained gel had a dry weight of $63.2 \mathrm{mg}$. Post polymer grafting (2.2.4), the reaction supernatant and wash solutions were pooled together and evaporated to dryness in a Buchi Rotavapor-RE Rotary Evaporator KRvr-TD-65/45 (Buchi Labortechnik AG, Flawil, Switerland). The dried residue containing ungrafted free poly(NIPAAm-co-tBAAm-co-AAc-co-MBAAm) and 
unreacted monomers was resuspended in a small volume of tetrahydrofuran (THF). The free copolymer was then precipitated from solution by the addition of 10 volumes of diethyl ether. The supernatant fraction containing dissolved monomers was carefully removed, rotary evaporated to dryness, and then redissolved in $100 \%$ (v/v) ethanol for ATR FT-IR analysis. The precipitated polymer was subsequently washed with diethyl ether, dried in a $60{ }^{\circ} \mathrm{C}$ oven for $20 \mathrm{~h}$ and accurately weighed, before finally dissolving in deuterated chloroform $\left(\mathrm{CDCl}_{3}\right)$ and analyzing the relative amounts of NIPAAm and tBAAm from the ${ }^{1} \mathrm{H}$ NMR spectrum of the polymer in a Bruker AV400 Nuclear Magnetic Resonance (NMR) Spectrometer (BrukerBioSpin Corporation, Billerica, MA, USA).

The lower critical solution temperature (LCST) of the copolymer was determined in the standard way $[16,21,22,24]$. The copolymer was resuspended at a concentration of $0.5 \%$

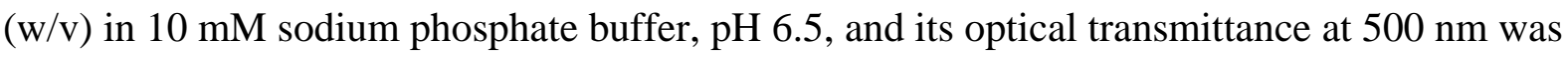
measured at various temperatures in a Cecil CE7500 UV/visible dual beam spectrophotometer (Cecil Instruments Ltd, Cambridge, UK) equipped with a water thermostatted cuvette holder.

The $\mathrm{H}^{+}$exchange capacity of the thermoCEX support was determined by titration according to a procedure supplied by GE Healthcare (method No. 30407; for determination of the ionic capacity of CM Sepharose media).

Protein contents in samples arising from batch binding and chromatography experiments were determined by UV spectrophotometry at $280 \mathrm{~nm}$ in quartz cuvettes in a Lambda $20 \mathrm{UV}$ VIS spectrophotometer (PerkinElmer Analytical Instruments, Shelton, CT, USA) or in a NanoDrop ${ }^{\mathrm{TM}} 1000$ micro-volume UV-Vis Spectrophotometer (Thermo Fisher Scientific, Wilmington, DE, USA). 


\section{Results and Discussion}

In this study, procedures described by Maharjan and coworkers [24] were improved upon to convert an underivatized beaded cross-linked Sepharose matrix into thermoresponsive cation exchange (thermoCEX) adsorbents featuring surface tethered lightly cross-linked thermoresponsive anionic copolymer chains, and the resulting materials were subsequently employed to demonstrate a new column arrangement (TCZR), specifically designed for thermoresponsive chromatography.

The manufacture of thermoCEX material presented herein differs from that described by Maharjan et al. [24] in two main respects, i.e. the use of Sepharose CL-6B in place of Sepharose 6 Fast Flow, and more importantly, the markedly different conditions employed for the crucial initial epoxy activation step prior to amine capping and immobilization of the initiator of polymerization, ACV (Fig. 1). The extent to which these changes impact on the loading and composition of immobilized poly(NIPAAm-co-tBAAm-co-AAc-co-MBAAm) on the final supports, and the temperature dependent LF binding behaviour, was thoroughly examined, before progressing to dynamic chromatographic experiments with thermally jacketed column and TCZR set ups, primarily, to confirm both the similarity and improvement of the thermoCEX adsorbent detailed herein to that originally described by Maharjan and coworkers [24], and second, to add further understanding to the concept/mechanisms proposed by the same authors.

\subsection{Manufacture and characterization of the thermoCEX adsorbent}

For physico-chemical characterization of support starting material, intermediate supports at every stage of the conversion (Fig. 1), pre and post polymerization reaction supernatants, and the final thermoCEX adsorbent itself, we employed a battery of tests (FT-IR, ATR FT-IR, ${ }^{1} \mathrm{NMR}$, gravimetric measurements and titration based assays for oxirane content and ion 
exchange capacity). The main findings from these are presented in Figures 4 and 5 and Table 1 , and described in the following text.

FT-IR spectra for dried supports from each stage during fabrication of thermoCEX matrices are shown in Figure 4. All spectra are normalized for peak height at $934 \mathrm{~cm}^{-1}$, as this is characteristic for the 3,6-anhydro moiety of Sepharose [30]. The spectrum for unmodified Sepharose CL-6B shows peaks corresponding to the functional groups expected of crosslinked agarose, i.e. alkyl $\mathrm{CH}_{2}$ bending (at 1474, 1419 and $1378 \mathrm{~cm}^{-1}$ ), alcohol C-O stretching (1190 and $1159 \mathrm{~cm}^{-1}$ ) and ether C-O-C stretching (1068 and $\left.1042 \mathrm{~cm}^{-1}\right)$. A pronounced broad peak at $1653 \mathrm{~cm}^{-1}$ corresponding to water $\mathrm{H}-\mathrm{O}-\mathrm{H}$ bending is also observed. This peak arises due to the hygroscopic nature of Sepharose, which tends to absorb atmospheric water after being dried.

No new peaks were introduced in the Sepharose CL-6B's FT-IR spectrum following activation with epichlorohydrin, but increases in peak heights in the $1474-1378 \mathrm{~cm}^{-1}$ region (alkyl, $\mathrm{CH}_{2}$ bend) and areas of peaks at 1068 and $1042 \mathrm{~cm}^{-1}$, were noted. The most striking of these changes, an enhanced peak at $1378 \mathrm{~cm}^{-1}$, is consistent with a rise in alkyl group content arising from additional $\mathrm{CH}_{2}$ groups of anchored glycidyl functions. Evidence for the introduction of oxirane moieties was tentatively indicated by a less obvious increase in length of the 'shoulder' at $1000-1030 \mathrm{~cm}^{-1}$ in the FT-IR spectrum, and was categorically confirmed by independent chemical assay (Table 1, $662 \mu \mathrm{mol} / \mathrm{g}$ dried support).

New changes in FT-IR spectrum were not observed following amine capping of epoxy activated Sepharose CL-6B. Given the relatively low epoxide density, this was not unexpected. Further, the loss of oxirane groups in $1200-1000 \mathrm{~cm}^{-1}$ range is likely offset by increases in peak signals corresponding to resulting secondary alcohols (C-O stretch, 1080 $\mathrm{cm}^{-1}$ ) and amines (C-N stretch, $\left.1200-1025 \mathrm{~cm}^{-1}\right)$. The expected amine N-H bending peak at ca. $1600 \mathrm{~cm}^{-1}$ is not clearly seen, and is likely obscured by the broad water peak at $1653 \mathrm{~cm}^{-1}$. 
Successful addition of the ACV initiator was confirmed following reaction with ACV, by two striking changes in the FT-IR spectrum, i.e. new peaks at $1736 \mathrm{~cm}^{-1}$ (carboxylic acid $\mathrm{C}=\mathrm{O}$ stretch) and $1552 \mathrm{~cm}^{-1}$ (azo $\mathrm{N}=\mathrm{N}$ stretch and/or amide $\mathrm{N}-\mathrm{H}$ bend). Some broadening between $1653 \mathrm{~cm}^{-1}$ (water $\mathrm{H}-\mathrm{O}-\mathrm{H}$ bending) and $1736 \mathrm{~cm}^{-1}$ (carboxylic acid $\mathrm{C}=\mathrm{O}$ stretch) consistent with the expectation of increased absorbance at $\sim 1670 \mathrm{~cm}^{-1}$ corresponding to amide $\mathrm{C}=\mathrm{O}$ stretching, was also noted. Gravimetric analysis indicated $\mathrm{ACV}$ had, following the amine capping step, been coupled to nearly $60 \%$ of the initially installed reactive epoxide sites (Table 1, $380 \mu \mathrm{mol} /$ dried support).

The spectrum of the thermoCEX activated matrix shows considerable growth of the peak at $1570 \mathrm{~cm}^{-1}$ (amide N-H bend), indicating presence of additional amide groups from the grafted copolymer chains (arising from NIPAAm, tBAAm and MBAAm). Peaks at 1736 $\mathrm{cm}^{-1}$ (carboxylic acid $\mathrm{C}=\mathrm{O}$ stretch) and $1670 \mathrm{~cm}^{-1}$ (amide $\mathrm{C}=\mathrm{O}$ stretch) also appear to have grown, indicating that the amide-containing units from NIPAAm, tBAAm and MBAAm and carboxylic acid-containing units from AAc have both been successfully grafted in significant amounts.

${ }^{1} \mathrm{H}$ NMR spectra of ungrafted free copolymer in $\mathrm{CDCl}_{3}$ (Fig. 5) indicated the successful inclusion of NIPAAm and tBAAm units into the polymer chains. A peak seen at $2.16 \mathrm{ppm}$ corresponds to protons on the carbon $\alpha$ to the carbon of the amide carbonyl group in the NIPAAm and tBAAm monomers, or possibly the carboxylic acid group on AAc. The methyl protons marked 'A' and 'B' give the characteristic chemical shifts seen at 1.15 and 1.34 ppm respectively (Spectral Database for Organic Compounds, National Institute of Advanced Industrial Science and Technology, Japan). Comparison of peak heights associated with these ' $A$ ' and 'B' protons (Fig. 5) indicated that monomers had been grafted with a NIPAAm to tBAAm ratio of $88: 12$ in the ungrafted copolymer. Assuming that the compositions of the free and matrix grafted copolymers are identical, then the ratio of 
NIPAAm: tBAAm: AAc of the subunits grafted onto the matrix is approximately 79:11:10 (Table 1). Using the same approach, Maharjan et al. [24] determined a 'NIPAAm: tBAAm: AAc' ratio closer to that of the initial monomer ratio employed in the polymer grafting reaction (i.e. 90:5:5) of 86:7:7.

Much higher 'on-support' polymer yields were obtained in the present study $c f$. Maharjan and co-workers' [24]. Consumption of the individual monomers by the ACV immobilized support was two to three fold higher $(13.2-32.5 \%$ cf. $6.5-10.1 \%$; Table 1$)$ leading to immobilized NIPAAm, tBAAm and AAc contents of 3676, 501 and $469 \mu \mathrm{mol} / \mathrm{g}$ of thermoCEX support respectively, $c f$. figures of 1895,165 and $154 \mu \mathrm{mol} / \mathrm{g}$ reported by Maharjan et al. [24]. The amount of immobilized poly(NIPAAm-co-tBAAm-co-AAc-coMBAAm) grafted onto ACV linked Sepharose CL-6B was gravimetrically determined as 67 $\mathrm{mg} / \mathrm{g}$ suction-drained thermoCEX support, confirming that $12.7 \%$ of the total monomers supplied for reaction had been grafted onto the ACV-linked matrix.

The significant differences noted here for copolymer composition and loading (Table 1) are unlikely to arise from the use of Sepharose CL-6B in place of Sepharose 6 Fast Flow given the gross similarities shared by these two media, and are instead much more likely to stem from the initial epoxide group density formed in the first step, and its subsequent impact on the immobilised ACV initiator density, and the kinetics and yield of the subsequent polymer grafting reaction.

In our work, we have employed the optimal ECH activation conditions described by Matsumoto and coworkers [27], i.e. $5 \% \mathrm{ECH}, 0.4 \mathrm{M} \mathrm{NaOH}, 2 \mathrm{~h}$ at $40{ }^{\circ} \mathrm{C}$. The latter introduces high levels of oxirane with minimal cross-linking and is ideally suited for modifying previously cross-linked chromatography media. These conditions routinely yield high and consistent levels of oxirane substitution with various cross-linked Sepharose (650 $750 \mu \mathrm{mol} / \mathrm{g}$ dried support) and Superose $(850-900 \mu \mathrm{mol} / \mathrm{g}$ dried support $)$ media. In this 
study, an oxirane density of $662 \mu \mathrm{mol} / \mathrm{g}$ dried matrix was determined using Sepharose CL-6B (Table 1). Maharjan et al. [24] did not report a value for oxirane content of their ECH activated Sepharose 6 Fast Flow support. However, our own measurements performed on ECH activated supports made under the conditions these authors described, yielded a low oxirane density of $371 \mu \mathrm{mol} / \mathrm{g}$ dried support. The high concentrations of ECH (30\%) and alkali $(\sim 0.7 \mathrm{M} \mathrm{NaOH})$, coupled with the extended reaction time $(21 \mathrm{~h})$ employed by Maharjan et al. [24], are documented to result in extensive cross-linking of the support and increased hydrolysis of introduced oxirane functions to yield glycerol groups [27,31-34].

In view of the similarity of conditions employed for the subsequent amine capping and ACV activation steps prior to graft polymerization in this and Maharjan and coworkers' study [24], the likely impact of doubling the initial oxirane content (in this work) is a similar fold increase in the immobilized ACV content. This increased availability of initiator sites can be expected to allow for the generation of a larger number of grafted polymer chains, making a significant contribution to the higher yield seen for our grafting reactions $c f$. those described by Maharjan et al. [24].

The polymerisation rate during free radical polymerization is typically dependent on the square root of the initiator concentration $[35,36]$, while increased concentrations of initiator have been consistently shown to increase polymerization yields [37,38]. The effect of initiator concentration on yield is expected to be particularly pronounced for surface initiated polymerizations which achieve relatively low yields, as in this instance, the rateslowing effects of polymer chain viscosity and low monomer concentration do not result in faster, higher initiator concentration polymerizations being 'pulled back' relative to their lower initiator concentration analogues as they near the end of their polymerization process.

Grafting of polymer chains on the matrices was accompanied by the generation of significant amounts of free polymer in the supernatant (gravimetrically determined as $24.7 \%$ 
of the total monomers supplied). The presence of this free polymer can be accounted for by two factors in particular: (i) splitting of azo initiator into one immobilised radical and one free radical during initiation, allowing initiation to occur from molecules free in solution as well as those on the matrix surface; and (ii) radical chain transfer from immobilised polymer chain to free monomer, allowing further initiation from molecules which are free in solution. As the degree to which these two mechanisms occur depends upon the concentration of azo initiators and immobilised radical chains, it can be expected that the approximate 1:2 ratio of immobilised to free polymer seen for our work (i.e. 1:2) will be similar in Maharjan and coworkers' study [24], although the total amount of polymer generated per $\mathrm{g}$ of matrix is more than two fold higher in our work.

The LCST of the pNIPAAm homopolymer is widely reported as $c a .32{ }^{\circ} \mathrm{C}[8,9]$, but can be variably tuned to occur at lower or higher temperatures simply by incorporating various quantities of hydrophobic or hydrophilic monomers in the pre-polymerization mix $[3,39,40]$. For example, copolymerization of NIPAAm with the more hydrophobic tBAAm monomer results is a reduction in LSCT [39,40], whilst conversely, integrating more hydrophilic monomers has the opposite effect of increasing the LCST [39]. The production of thermoresponsive copolymers possessing ion exchange functionality, while retaining pNIPAAm's LSCT can be achieved by balancing the incorporation of charged monomers with ones more hydrophobic than NIPAAm [19-22,24]. Figure 6 compares the temperature dependent 'hydrophilic coil - hydrophobic globule' transition of the ungrafted free poly(NIPAAm-co-tBAAm-co-AAc-co-MBAAm) prepared in this work with that produced by Maharjan et al. [24]. Both NIPAAm copolymers exhibit the characteristic sharp decrease in optical transmittance across a relatively narrow temperature range that is expected of polymers exhibiting inverse temperature solubility behaviour, although, the temperature range over which the full phase transition occurs is considerably wider for the copolymer in 
this work $\left(30-41{ }^{\circ} \mathrm{C} c f\right.$. $28-34{ }^{\circ} \mathrm{C}$, Fig. 6); a finding entirely in keeping with the copolymer's lower NIPAAm content (79\% cf. $86 \%$ ). Despite the differences in NIPAAm content and monomer composition (Table 1), the temperature at which $50 \%$ optical transmittance occurs, i.e. the LCST [16,22,24], differs by only $2{ }^{\circ} \mathrm{C}$, i.e. $32{ }^{\circ} \mathrm{C}$ for the '79:11:10' copolymer in this work $c f .30^{\circ} \mathrm{C}$ for Maharjan and co-workers' '86:7:7' copolymer [24].

\subsection{Temperature dependent batch adsorption of LF on thermoCEX adsorbents}

Figure 7a compares the effect of temperature on the adsorption of LF to the thermoCEX adsorbents prepared in this study with Maharjan and coworkers' analogous data [24] obtained for their adsorbent material. In both cases, and in stark contrast to the solution temperature mediated phase transition behaviour exhibited by both free copolymers in Fig. 6, incremental increases in temperature from 20 to $50{ }^{\circ} \mathrm{C}$ were met with gradual increases in LF binding capacity. In keeping with Maharjan et al.'s hypothesis [24], at the lowest temperature of 20 ${ }^{\circ} \mathrm{C}$ the copolymer is expected to be fully extended and hydrophilic, and the spacing between neighbouring carboxylic acid moieties in the immobilized copolymer network is envisaged to be high. Not surprisingly, LF binding capacity is at its lowest value for both thermoCEX supports at this temperature $(12 \mathrm{mg} / \mathrm{ml}$-this work; $13 \mathrm{mg} / \mathrm{ml}$ - ref. 24). However, as the temperature is gradually raised from this point, the immobilized copolymer starts to collapse, becoming increasingly hydrophobic and flattening against the surface of the base matrix. In so doing, previously buried negative charges become increasingly exposed and their density per unit surface rises as the distance between them drops. The net effect of these changes in surface hydrophobicity and charge density on the binding of LF, is increased tightness of binding strength and capacity for both thermoCEX adsorbents (Figs 7a, 7b and Table 1). It is clear however, that the effect of temperature on LF capacity increase is more pronounced for 
the thermoCEX adsorbent made in this work. For this adsorbent, the capacity rises nearly 5 fold from $12 \mathrm{mg} / \mathrm{ml}$ at $20^{\circ} \mathrm{C}$ to $58 \mathrm{mg} / \mathrm{ml}$ at $50{ }^{\circ} \mathrm{C}, c f .3 .4$ fold $\left(13 \mathrm{mg} / \mathrm{ml}\right.$ at $20{ }^{\circ} \mathrm{C}$ to 44 $\mathrm{mg} / \mathrm{ml}$ at $50{ }^{\circ} \mathrm{C}$ ) for Maharjan et al.'s material [24]. Figure 7b shows adsorption isotherms obtained for LF binding to the thermoCEX adsorbents prepared in this work in a $10 \mathrm{mM}$ sodium phosphate buffer, $\mathrm{pH} 6.5$, at temperatures of 20,35 and $50{ }^{\circ} \mathrm{C}$, and Table 2 summarizes the Langmuir binding parameters fitted to the data sets. At $20{ }^{\circ} \mathrm{C} \mathrm{LF}$ binding is weak $\left(\mathrm{K}_{\mathrm{d}}=1.66 \mathrm{mg} / \mathrm{ml}\right)$ and of low capacity, $\left(\mathrm{q}_{\max }=21.9 \mathrm{mg} / \mathrm{ml}\right)$, but as the temperature is raised, both binding strength and capacity rise significantly; paired values of $q_{\max }$ and $K_{d}$ respectively reaching $\sim 40 \mathrm{mg} / \mathrm{ml}$ and $0.83 \mathrm{mg} / \mathrm{ml}$ at $35^{\circ} \mathrm{C}$, and $\sim 56 \mathrm{mg} / \mathrm{ml}$ and $<0.1 \mathrm{mg} / \mathrm{ml}$ at $50{ }^{\circ} \mathrm{C}$. Very similar behaviour was noted by Maharjan et al. [24]. However, while binding performance was almost identical at $20^{\circ} \mathrm{C}\left(\mathrm{q}_{\max }=24 \mathrm{mg} / \mathrm{ml}, \mathrm{K}_{\mathrm{d}}=1.86 \mathrm{mg} / \mathrm{ml}\right.$; initial slope $=$ $12.9 \mathrm{ml} / \mathrm{ml}$ ) to that observed herein (Table 2), at $50{ }^{\circ} \mathrm{C}$ the magnitude of the initial slopes of the isotherms $(610 c f .121 \mathrm{ml} / \mathrm{ml})$ indicates that the thermoCEX adsorbent in this study binds LF $>5$ times more tightly than Maharjan and coworkers' material [24]. The much higher copolymer content, increased hydrophobicity and $>3$ fold higher charge density on this adsorbent (Table 1) are obvious reasons for the observed improvement in LF binding at higher temperatures.

The marked difference in temperature dependent behaviour noted above for phase change of the free copolymer and LF binding of the immobilized copolymer, deserves comment. The chain collapse of pNIPAAm based polymers tethered to a surface is generally regarded as very different and more complex to that in free solution and is influenced by grafting density, architecture and molecular weight of the tethered polymer chains, and overall graft thickness [41 - 45]. The reduced freedom of movement of surface tethered polymer segments within the cross-linked copolymer network results in less abrupt collapse than in free solution [45]. At temperatures above the LCST, chain collapse occurs less readily 
for our copolymer in free solution $c f$. Maharjan and coworker's (see Fig. 6). This apparent disadvantage however, appears to be substantially outweighed in tethered form (Fig. 7a), and is most likely due to a combination of higher grafting density, and greater mass/thickness of the attached copolymer graft (Table 1). The magnitude of pNIPAAm chain collapse above the LCST is reported to decrease with decreasing grafting density and polymer molecular weight [44]. Further, at low surface coverage thermoresponsive polymer networks are considered to be relatively immobile and confined close to the surface to which they are anchored, but with increasing coverage, the mobility of polymer segments, especially in the outermost regions of the polymer graft, increases [45].

\subsection{Chromatography of LF in jacketed columns containing thermoCEX matrix}

The temperature-dependent protein sorption behaviour of thermoresponsive ion exchange adsorbents described in this and other work [19-25,46] makes them attractive prospects for regenerate-free isocratic liquid chromatography, potentially providing viable solutions to issues such as sub-optimal elution/cleaning performance and excessive buffer consumption/waste generation. However, with very few exceptions [47], all reported investigations on thermoresponsive liquid chromatography use conventional fixed-bed columns filled with thermoresponsive adsorbents, and the whole column is tempered by a water bath, a water jacket connected to a water bath, or a column oven [16-19,24,26]. Typically, protein adsorption takes place at elevated column temperatures, and protein desorption is forced by cooling down the whole column. Using this approach, in combination with thermoresponsive cation exchange supports of similar construction to those employed in this work (i.e. cross-linked beaded $6 \%$ agarose matrix grafted with poly (pNIPAAm-cotBAAm-co-AAc-co-MBAAm); Table 1), Maharjan and coworkers [24] reported that: (i) the column's dynamic binding capacity for LF rose from $8 \mathrm{mg} / \mathrm{ml}$ at $20^{\circ} \mathrm{C}$ to $27 \mathrm{mg} / \mathrm{ml}$ at $50{ }^{\circ} \mathrm{C}$ 
(u was not defined); and (ii) following loading at $50{ }^{\circ} \mathrm{C}, 47 \%$ of the adsorbed $\mathrm{LF}$ could be recovered simply by lowering the column temperature shift to $20^{\circ} \mathrm{C}$.

Similar results were obtained in this study using packed columns of the higher capacity thermoCEX matrix (Fig. 8). A narrower operating temperature range of $42-22{ }^{\circ} \mathrm{C}$ (corresponding to $10{ }^{\circ} \mathrm{C}$ either side of the free copolymer's LCST; Fig. 7a), and mobile phase velocity of $300 \mathrm{~cm} / \mathrm{h}$ were employed; under these conditions, total dynamic binding capacities of 7.2 and $35.4 \mathrm{mg} / \mathrm{ml}$ were determined at the lower and higher temperatures, respectively. In Figure 8a the column was saturated with LF at the lower temperature. A transient increase in column temperature to $42{ }^{\circ} \mathrm{C}$ towards the end of washing phase failed to enhance or reduce LF desorption $c f$. operation at $22{ }^{\circ} \mathrm{C}$, and all of the adsorbed LF was recovered in the subsequent $1 \mathrm{M} \mathrm{NaCl}$ elution step. In stark contrast, following LF loading and washing at $42{ }^{\circ} \mathrm{C}$ a single cooling transition under binding conditions desorbed $44 \%$ of the bound LF (Fig. 8b) and multiple transitions (Fig. 8c) raised this slightly to 51\%. In both of these cases following thermal cycling, most of the residually bound LF was effectively desorbed in the final $1 \mathrm{M} \mathrm{NaCl}$ elution step (mass balances closing to $94 \%$ and $101 \%$ respectively for Fig. $8 \mathrm{~b}$ and $\mathrm{c}$ respectively). From Figure $8 \mathrm{c}$ it is striking to note that $\mathrm{LF}$ was only desorbed by cooling ( 5 steps in all) and further that all four 'hot' transitions promoted a tightening of LF adsorption, in keeping with earlier observations (Fig. 7b \&Table 2).

\subsection{TCZR chromatography of LF}

One significant drawback of tempering the entire column is the strong tailing of elution peaks observed (Figs 8 b \& c), a consequence of the 'weak' conditions typical of isocratic elution. Another disadvantage is that tempering the whole column renders continuous operation impossible, i.e. it permits only batch-wise operation. The TCZR concept proposed earlier (section 2.5, and Fig. 3), in which only a small part of the column is cooled via a computer 
controlled motor-driven travelling Peltier block arrangement (Fig. 2), affords a means of overcoming both of the above issues.

Figure 9 presents the chromatogram arising from the first test of the TCZR system employing thermoCEX adsorbents and LF as the model binding species. With the column held at a temperature of $35{ }^{\circ} \mathrm{C}$, LF was supplied until near saturation of the thermoCEX matrix had been achieved. Following washing with loading buffer, the amount of protein still bound to the support was estimated to be $92.8 \mathrm{mg}$ (equivalent to $25.2 \mathrm{mg} / \mathrm{ml}$ ). Eight successive temperature-mediated elution steps were then conducted by driving the cooling assembly at its lowest possible axial velocity, $\mathrm{v}_{\mathrm{c}}$, of $0.1 \mathrm{~mm} / \mathrm{s}$ (corresponding to $\sim 5 \%$ of $\mathrm{u}_{\mathrm{i}}$ ). Nearly $65 \%$ (59.9 mg) of the previously adsorbed LF was eluted from the column (Table 3), and the residually bound LF was subsequently desorbed at $35{ }^{\circ} \mathrm{C}$ using equilibration buffer supplemented $1 \mathrm{M} \mathrm{NaCl}$. Striking features of the chromatogram, caused by accumulation of desorbed LF in the narrow travelling cooling zone, are the sharp elution peaks without any peak tailing. The first peak's LF concentration was actually higher than that of the feed. This peak alone accounted for $54.4 \%$ of total LF eluted (i.e. all 8 peaks combined; Table 3). Even so, protein was still being eluted in all subsequent cycles (even in the $8^{\text {th }}$ ); most likely because of the thermoCEX Sepharose CL-6B matrix's slow intra-particle pore diffusion kinetics. By moving the cooling zone along the separation column, proteins are desorbed with the region of reduced temperature because of the reduced binding affinity under these conditions (Table 2). Given that the fluid phase in the resin pores is stagnant [48], desorbed proteins must diffuse out of the pores in order to enter the interstitial liquid to be transported by convection towards the column outlet. This step, often identified as the major factor contributing to peak dispersion in liquid chromatography [48], would also appear to represent a problem for the TCZR chromatography approach. If the time for the diffusion of a previously adsorbed protein out of the pores is longer than that of the moving cooling zone's 
contact with a given part of the stationary phase, then protein still remaining within the pores in this region will rebind to the support once the cooling zone has passed by and the temperature rises back towards its initial value (i.e. prior to its encounter with the travelling cooling zone; $35^{\circ} \mathrm{C}$ in this case). It follows that protein species with longer diffusion paths can eventually be eluted, if multiple movements of the cooling zone are employed.

The main focus of the second TCZR test (Fig. 10) was to examine the impact of varying the ratio of the velocities of the elution front and the cooling zone on chromatographic performance. For this, using identical LF loading, mobile phase velocity and column temperatures to those employed in the first test (Fig. 9), the cooling zone was moved along the whole column a total of six times at different speeds. For the first and second movements of the cooling zone, $\mathrm{v}_{\mathrm{c}}$ was set at values corresponding to $100 \%$ (1.9 $\mathrm{mm} / \mathrm{s})$ and $c a .50 \%(1.0 \mathrm{~mm} / \mathrm{s})$ of $\mathrm{u}_{\mathrm{i}}$, and the remaining four movements were conducted at $\mathrm{v}_{\mathrm{c}}$ $=0.1 \mathrm{~mm} / \mathrm{s}$, i.e. the same as that employed in the first test. It is clear that the ' $\mathrm{v}_{\mathrm{c}}=0.1 \mathrm{~mm} / \mathrm{s}$ ' elution incidents in the second test closely resemble those in the first (compare Figs 9 and 10). For this reason, only the first three movements are considered in the discussion of the influence of $\mathrm{v}_{\mathrm{c}}$ on system performance. Clearly, the amount of protein eluted by a single movement of cooling zone increases strongly with decreasing $\mathrm{v}_{\mathrm{c}}$. For example, less than 0.1 $\mathrm{mg}$ of LF was eluted from the column at $\mathrm{v}_{\mathrm{c}}=1.9 \mathrm{~mm} / \mathrm{s}$, increasing to $\sim 3.3 \mathrm{mg}$ at $\mathrm{v}_{\mathrm{c}}=1 \mathrm{~mm} / \mathrm{s}$, and reaching $29.3 \mathrm{mg}$ at $\mathrm{v}_{\mathrm{c}}=0.1 \mathrm{~mm} / \mathrm{s}$ (Table 3). These dramatic differences cannot be attributed to slow pore diffusion alone. A second explanation can be found based on the impact of cooling zone velocity on the minimum temperatures attained within the discrete regions of the column it contacts. At $\mathrm{v}_{\mathrm{c}}=1 \mathrm{~mm} / \mathrm{s}$ the temperature in the cooling zone is $c a$. $10.1^{\circ} \mathrm{C}$ higher than that at $\mathrm{v}_{\mathrm{c}}=0.1 \mathrm{~mm} / \mathrm{s}$, and thus the eluting power of the cooling zone is considerably reduced. 
The main reason, however, for the low performance of the TCZR at the higher cooling zone velocities is likely to be found in the ratio between the $v_{c}$ and $u_{i}$. Examination of the isotherm data (Fig. 7, Table 2) confirms that, despite much reduced LF binding affinity at lower temperatures, binding is not completely eradicated. Thus, the velocity of the travelling isocratic elution front is significantly smaller than that of the mobile phase.

In cases where $\mathrm{v}_{\mathrm{c}}$ equals $\mathrm{u}_{\mathrm{i}}$ or $0.5 \mathrm{u}_{\mathrm{i}}$, the cooling zone will move faster than the elution front, and thus the elution peak slips back into a region of elevated temperature, and so the protein rebinds.

\section{Conclusions}

An integrated approach to temperature-controlled chromatography, comprising copolymer modified beaded agarose adsorbents and a novel travelling cooling zone reactor (TCZR) arrangement, is described in this study. Published procedures for transforming underivatized cross-linked Sepharose matrices into thermoresponsive cation exchange (thermoCEX) adsorbents, featuring surface tethered lightly cross-linked thermoresponsive anionic copolymer chains [24], were substantially improved upon. The resulting adsorbent materials displayed superior temperature regulated LF binding performance, i.e. identical low affinity binding at $20{ }^{\circ} \mathrm{C}$, but much higher affinity at higher temperature, which conferred dual operational advantages during temperature-controlled chromatography, namely the use of a reduced temperature for $\mathrm{LF}$ adsorption $\left(42 c f .50{ }^{\circ} \mathrm{C}\right)$, whilst still retaining a capacity advantage of $>30 \%\left(35.4 \mathrm{mg} / \mathrm{ml}\right.$ at $42{ }^{\circ} \mathrm{C} c f .27 \mathrm{mg} / \mathrm{ml}$ at $\left.50{ }^{\circ} \mathrm{C}\right)$. ThermoCEX adsorbents were subsequently employed to demonstrate the new TCZR arrangement, one specifically designed for temperature-controlled chromatography. As the cooling zone travelled along the column, LF, previously adsorbed on the stationary phase at $35^{\circ} \mathrm{C}$, was desorbed in the form of sharp, concentrated peaks. Intra-particle diffusion of desorbed protein out of the pores of 
the support and the ratio between the velocities of the cooling zone and mobile phase were identified as the main parameters affecting the TCZR's performance. The use of thermoresponsive adsorbents with smaller particle diameters (in nuce shorter diffusion paths) or, better still, appropriately functionalized monolithic chromatography media (not subject to diffusion-controlled mass transfer) are possible routes to better TCZR system performance. The adaptation of the TCZR system for continuous liquid chromatography is also envisaged to bring added benefits, as in this instance protein loading and elution would occur concurrently within different regions of the TCZR.

Despite the significant improvements in thermoresponsive anionic copolymer loading and operational performance noted here, further advances in support functionalization are required, principally to: (i) raise protein binding capacity (the $\mathrm{H}^{+}$exchange and LF binding capacities of the thermoCEX matrix in this work were less than half those of CM Sepharose Fast Flow); (ii) improve desorption efficiency; and (iii) lower the operating temperature range. The current design, combining thermoresponsive and charged monomers within the same polymeric chains or network, is unlikely to deliver temperature-sensitive ion exchange adsorbents possessing charge densities and protein binding capacities similar to those commercial ion exchangers, whilst simultaneously retaining desirable thermoresponsive properties. Uncoupling 'thermoresponsiveness' from 'charge' may be the solution, and could conceivably be achieved by grafting thermoresponsive chains directly into the surfaces of commercial high capacity ion exchangers. Finally, in order to extend the applicability of temperature-controlled chromatography to the separation of proteins less thermally stable than LF, temperature transitions should ideally take place at lower temperatures using appropriately functionalized media. With surface grafted polymers based on NIPAAm, this can be achieved by increasing the content of hydrophobic monomers such as tBAAm 
$[3,39,40]$. Alternatively, newer non-NIPAAm PEG based alternatives with even better properties [49-51] also invite investigation.

\section{Acknowledgements}

This work was funded by the European Framework 7 large scale integrating collaborative project 'Advanced Magnetic nano-particles deliver smart Processes and Products for Life' (MagPro²Life, CP-IP 229335-2).

\section{References}

[1] T.M. Przybycien, N.S. Pujar, L.M. Steele, Curr. Opin. Biotechnol. 15 (2004) 469-478.

[2] G. Jagschies, BioPharm Inter. 21 (October) (2008) 72.

[3] Maharjan, P., Woonton, B.W., Bennett, L.E., Smithers, G.W., K. DeSilva, M.T.W. Hearn, Innov. Food Sci. Emerg. Technol. 9 (2008) 232-242.

[4] Taylor, L. D., Cerankowski, J. Polym. Sci., Part A: Polym. Chem., 13 (1975) 2551-2570.

[5] I.Y. Galaev, B. Matthiasson, Trends Biotechnol. 17 (1999) 335-340.

[6] A.S. Hoffman, P. Stayton, Macromol. Symp. 207 (2004) 139-151.

[7] N. Matsuda, T. Shimizu, M. Yamato, T. Okano, Adv. Mater. 19 (2007) 3089-3099.

[8] M. Heskins, J.E. Guillet, J. Macromol. Sci. Chem. A 2 (1968) 1441-1455.

[9] K. Kubota, S. Fujishige, I. Ando, J. Phys. Chem., 94 (1990) 5154-5158.

[10] H.G. Schild, Prog. Polym. Sci. 17 (1992) 163-249.

[11] M. Gewehr, K. Nakamura, N. Ise, H. Kitano, Makromol. Chem. 193 (1992) 249-256.

[12] K. Hosoya, E Sawada, K. Kimata, T. Araki, N. Tanaka, J.M.J. Fréchet, Macromolecules, 27 (1994) 3973-3976.

[13] K. Hosoya, K. Kimata, T. Araki, N. Tanaka, J.M.J. Fréchet, Anal. Chem. 67 (1995) 1907-1911. 
[14] B. P. Adrados, I.Y. Galaev, K. Nilsson, B. Mattiasson, J. Chromatogr. A 930 (2001) 7378.

[15] T. Yakushiji, K. Sakai, A. Kikuchi, T. Aoyagi, Y. Sakurai, T. Okano, Anal. Chem. 71 (1999) 1125-1130.

[16] H. Kanazawa, Y. Kashiwase, K. Yamamoto, Y. Matsushima, A Kikuchi, Y. Sakurai, T. Okano, Anal. Chem. 69 (1997) 823-830.

[17] H.E. Teal, Z. Hu, D.D. Root, Anal. Biochem. 283 (2000) 159-165.

[18] E. Ayano, Y. Okada, C. Sakamoto, H. Kanazawa, A. Kikuchi, T. Okano, J. Chromatogr. A, 1119 (2006) 51-57.

[19] J. Kobayashi, A. Kikuchi, K. Sakai, T. Okano, J. Chromatogr. A, 958 (2002) 109-119.

[20] J. Kobayashi, A. Kikuchi, K. Sakai, T. Okano, Anal. Chem. 75 (2003) 3244-3249.

[21] C. Sakamoto, Y. Okada, H. Kanazawa, E. Ayano, T. Nishimura, M. Ando, A. Kikuchi, T. Okano, J. Chromatogr. A. 1030 (2004) 247-253.

[22] E. Ayano, K. Nambu, C. Sakamoto, H. Kanazawa, A. Kikuchi, T. Okano, J. Chromatogr. A 1119 (2006) 58-65.

[23] H. Kanazawa, M. Nishikawa, A. Mizutani, C. Sakamoto, Y. Morita-Murase, Y. Nagata, A. Kikuchi, T. Okano, J. Chromatogr. A 1191 (2008) 157-161.

[24] P. Maharjan, M.T.W. Hearn, W.R. Jackson, K. DeSilva, B.W. Woonton, J. Chromatogr A 1216 (2009) 8722-8729.

[25] K. Nagase, J. Kobayashi, A. Kikuchi, Y. Akiyama, H. Kanazawa, M. Annaka, T. Okano, Biomacromolecules 11(2010) 215-223.

[26] K. Yoshizako, Y. Akiyama, H. Yamanaka, Y. Shinohara, Y. Hasegawa, E. Carredano, A. Kikuchi, T. Okano, Anal. Chem., 74 (2002) 4160-4166.

[27] I. Matsumoto, Y. Mizuno and N. Seno, J. Biochem. 85 (1979) 10191-1098. 
[28] G.T Hermanson, A.K. Mallia, P.K. Smith, Immobilized affinity ligand techniques, Academic Press, London, 1992.

[29] L. Sundberg. L. and J. Porath, J. Chromatogr. 90 (1974) 87-98.

[30] M.D. Oza, R. Meena, K. Prasad, P. Paul, A.K. Siddhanta, Carbohydr. Polym. 81 (2010) 878-884.

[31] J. Porath, N. Fornstedt, J. Chromatogr. 51 (1970) 479-489.

[32] J. Porath, J.-C. Janson, T. Låås, J. Chromatogr. 60 (1971) 167-177.

[33] J. Porath, L. Sundberg, Nature New Biol. 238 (1972) 261-262.

[34] C.R. Lowe, P.D.G. Dean, Affinity Chromatography, John Wiley and Sons, New York, 1974.

[35] G.C. Eastmond, G. C., in Comprehensive Chemical Kinetics, Vol. 14A, C. H. Bamford and C. F. H. Tipper, eds., American Elsevier, New York, 1976.

[36] G. Odian, Principles of Polymerization, $4^{\text {th }}$ Edition, Wiley-Interscience, NY, USA, 2004.

[37] P.A. Weerts, J.L.M. Vanderloos, A.L. German, Makromol Chem. 190 (1989) 777-788.

[38] M. Jain, R.A Vora, U.S. Satpathy, Eur. Polym. J. 39 (2003) 2069-2076.

[39] A.S. Hoffman, P. Stayton, V. Bulmus, G. Chen, J. Chen, C. Cheung, A. Chilkoti, Z. Ding, L. Dong, R. Fong, C.A. Lackey, C. J. Long, M. Miura, J.E. Morris, N. Murthy, Y. Nabeshima, T.G. Park, O.W. Press, T. Shimoboji, S. Shoemaker, H.J. Yang, N. Monji, R.C. Nowinski, C.A. Cole, J.H. Priest, J.M. Harris, K. Nakamae, T. Nishino, T. Miyata, J. Biomed. Mater. Res. 52 (2000) 577-586.

[40] Y. Yoshimatsu, B.K. Lesel, Y. Yonamine, J.M. Beierle, Y. Hoshino, K.J. Shea, Angew. Chem. Int. Ed. 51 (2012) 2405-2408.

[41] J. Zhang, R. Pelton, Colloids Surf. A 156 (1999) 111-122.

[42] H. Yim, M.S. Kent, D.L. Huber, Macromolecules 36 (2003) 5244-5251.

[43] S. Mendez, J.G. Curro, J.D. McCoy, G.P Lopez, Macromolecules 38 (2005) 174-181. 
[44] K.N. Plunkett, Z., Xi, J.S. Moore, D.E. Leckband, Langmuir 22 (2006) 4259-4266.

[45] M. Andersson, S. Hietala, H. Tenhu, S.L. Maunu, Colloid Polym. Sci. 284 (2006) 12551263.

[46] K. Nagase, S.F. Yuk, J. Kobayashi, A. Kikuchi, Y. Akiyama, H. Kanazawa, T. Okano, J. Mater. Chem. 21 (2011) 2590-2593.

[47] H. Yagi, K. Yamamoto, T. Aoyagi, J. Chromatogr. B, 876 (2008) 97-102.

[48]. U. Tallarek, F.J. Vergeldt, H. Van As, J. Phys. Chem. B 103 (1999) 7654-7664.

[49] J-F. Lutz, Ö. Akdemir, A. Hoth, J. Am. Chem. Soc. 128 (2006) 13046-13047.

[50] J-F. Lutz, A. Hoth, Macromolecules 39 (2006) 893-896.

[51] J.P. Magnusson, A. Khan, G. Pasparakis, A.O. Saeed, W. Wang, C. Alexander, J. Am. Chem. Soc. 130 (2008) 10582-10853.

\section{Figure legends:}

Fig. 1. Schematic illustration of steps involved in converting Sepharose CL-6B into thermoCEX adsorbents (see text for details).

Fig. 2. CAD drawings of (a) the TCZR assembly and (b) temperature zone (blown up crosssection). Control devices are integrated in the closed box (a, left) and the separation column is encased within the temperature zone assembly and connected to a linear movable axis (a, right). The stainless steel column is packed with a thermoresponsive chromatography matrix. Mobile phase enters the column at the top and exiting flow is connected directly to an Äkta Purifier 10 chromatography system (not shown). The separation column is surrounded by (b) an assembly of Peltier elements, copper blocks (a central cooling block flanked on either side by a heating block) and heat sinks at the top and bottom of the whole arrangement. The 
Peltier elements are sandwiched between the top and middle and middle and bottom copper blocks.

Fig 3. Schematic illustrations of idealized single protein loading (top) and concentration profiles at different stages during batchwise TCZR operation (bottom). The profiles correspond to three discrete $\mathrm{z} / \mathrm{z}_{0}$ positions of the movable cooling zone, i.e. $<0,0.2 \& 0.8$. The assumptions made are full binding at elevated temperature and no binding at the reduced temperature in the cooling zone.

Fig. 4. FT-IR spectra recorded at various stages during the conversion of Sepharose CL-6B into thermoCEX adsorbents.

Fig. 5. ${ }^{1} \mathrm{H}$ NMR spectrum of free ungrafted copolymer in $\mathrm{CDCl}_{3}$. Peaks corresponding to hydrogen atoms of isopropylacrylamide and t-butylacrylamide side chains in the partial structure shown in the upper left corner are indicated by A and B respectively.

Fig. 6. Comparison of temperature-dependent optical transmittance $(500 \mathrm{~nm})$ profiles of $0.5 \%$ (w/v) solutions of ungrafted free poly(NIPAAm-co-tBAAm-co-AAc-co-MBAAm) prepared in this work $(\bigcirc)$ with that from Maharjan et al.'s [24] study $(\triangle)$.

Fig. 7. Effect of temperature on the binding of LF on thermoCEX Sepharose CL-6B: (a) illustrates a comparison of the effect of temperature variation on LF adsorption capacity of the thermoCEX material employed in this work with a starting concentration of $c_{0}=10 \mathrm{mg} / \mathrm{ml}$ (O) with that reported in Maharjan and coworkers' [24]) study $\left(\mathrm{c}_{0}=5 \mathrm{mg} / \mathrm{ml} ; \triangle\right)$; and (b) shows equilibrium binding isotherms at $20{ }^{\circ} \mathrm{C}(\square), 35^{\circ} \mathrm{C}(\boldsymbol{\square})$ and $50{ }^{\circ} \mathrm{C}(\bigcirc)$ The solid lines 
through the data points in (b) represent fitted Langmuir curves with parameter values presented in Table 2.

Fig. 8. Chromatograms arising from three separate experiments $(a-c)$ conducted with LF and jacketed chromatography columns containing thermoCEX matrix. Columns were saturated with $\mathrm{LF}$ at either $42^{\circ} \mathrm{C}(\mathrm{b} \& \mathrm{c})$ or $22^{\circ} \mathrm{C}(\mathrm{a})$, and washed at the binding temperature, prior to changing the column and mobile phase temperature once (a \& b) or multiple coolingheating transitions (c). Residual bound LF was subsequently eluted at $22{ }^{\circ} \mathrm{C}$ using a $1 \mathrm{M}$ $\mathrm{NaCl}$ step gradient. The arrows indicate onset of the loading (L), washing (W) and $\mathrm{NaCl}$ mediated elution (E), and the unshaded and shaded grey areas indicate operating temperature of $42{ }^{\circ} \mathrm{C}$ and $22{ }^{\circ} \mathrm{C}$ respectively. The solid and dashed lines represent the absorbance and conductivity signals respectively.

Fig. 9. Chromatogram arising from a TCZR test employing eight movements of the cooling zone at a velocity, $\mathrm{v}_{\mathrm{c}}$, of $0.1 \mathrm{~mm} / \mathrm{s}$. The unshaded indicates column operating temperature of $35^{\circ} \mathrm{C}$, the shaded grey shade zones indicate movement of the cooling zone. The solid and dashed lines represent the absorbance and conductivity signals respectively.

Fig. 10. Chromatogram arising from a TCZR test employing seven movements of the cooling zone at different velocities, i.e. $1.9 \mathrm{~mm} / \mathrm{s}$ for the first, $1 \mathrm{~mm} / \mathrm{s}$ for the second and $0.1 \mathrm{~mm} / \mathrm{s}$ for the subsequent movements. The unshaded indicates column operating temperature of $35^{\circ} \mathrm{C}$, the shaded grey zones indicate movement of the cooling zone. The solid and dashed lines represent the absorbance and conductivity signals respectively. 


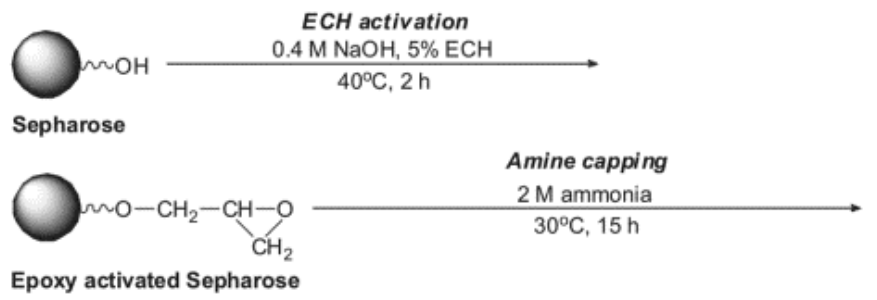

ACV immobilization

$Q \mathrm{~N} \mathrm{O}-\mathrm{CH}_{2}-\underset{1}{\mathrm{CH}}-\mathrm{CH}_{2}-\mathrm{NH}$ $A C V, E E D Q, D M F$

Amine terminated Sepharose

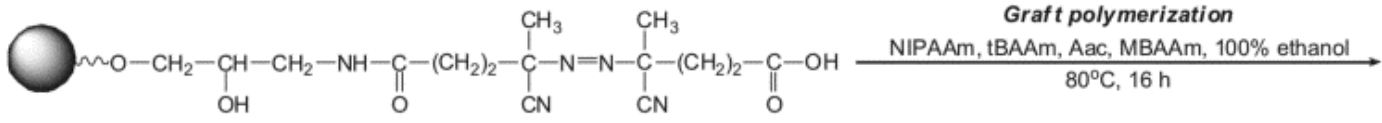

ACV immobilized Sepharose

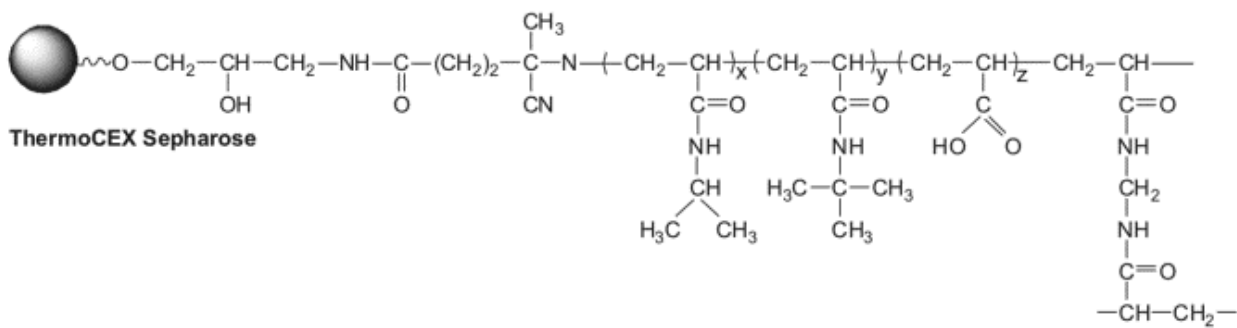

Fig. 1 

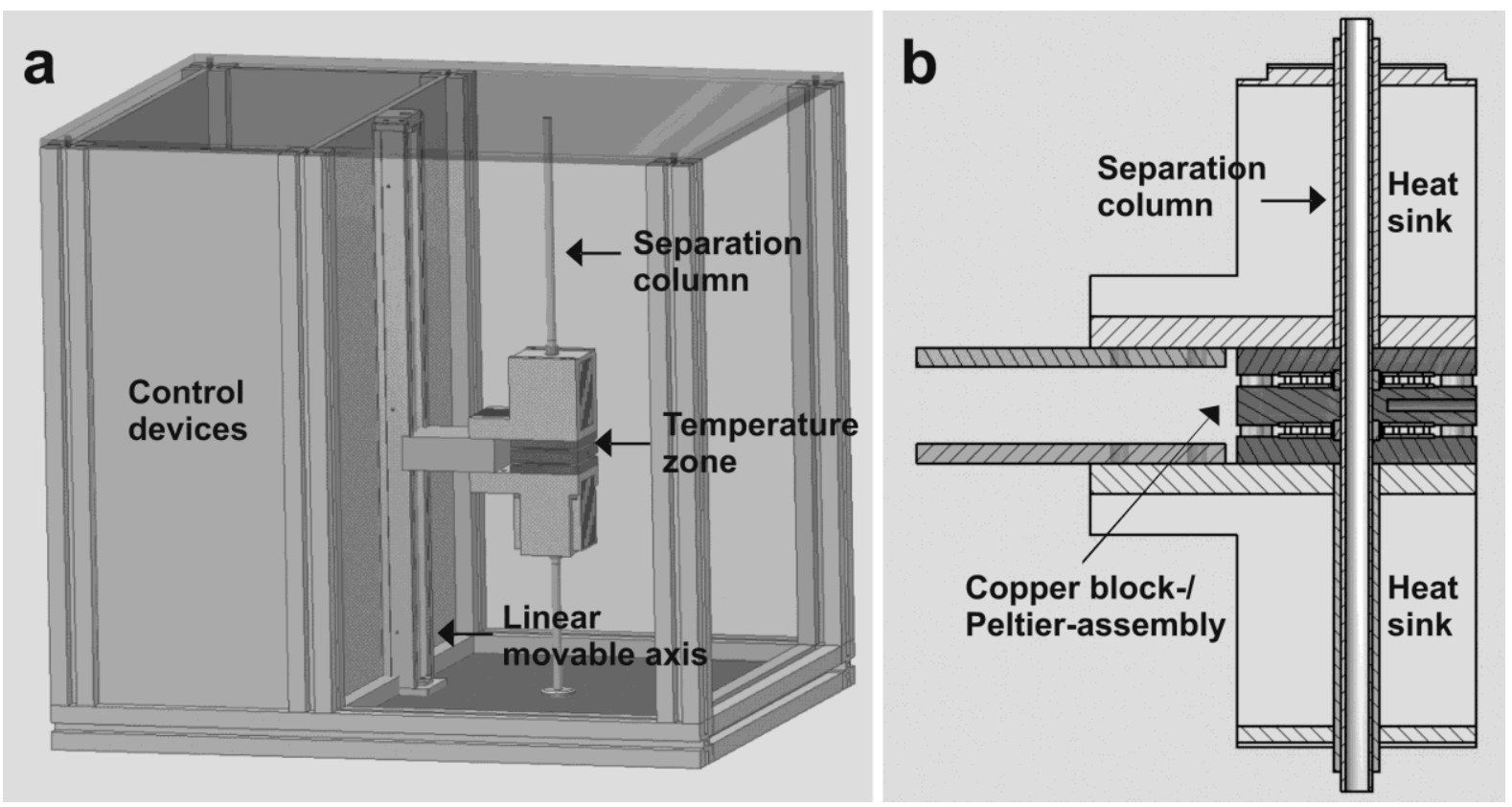

Fig. 2 


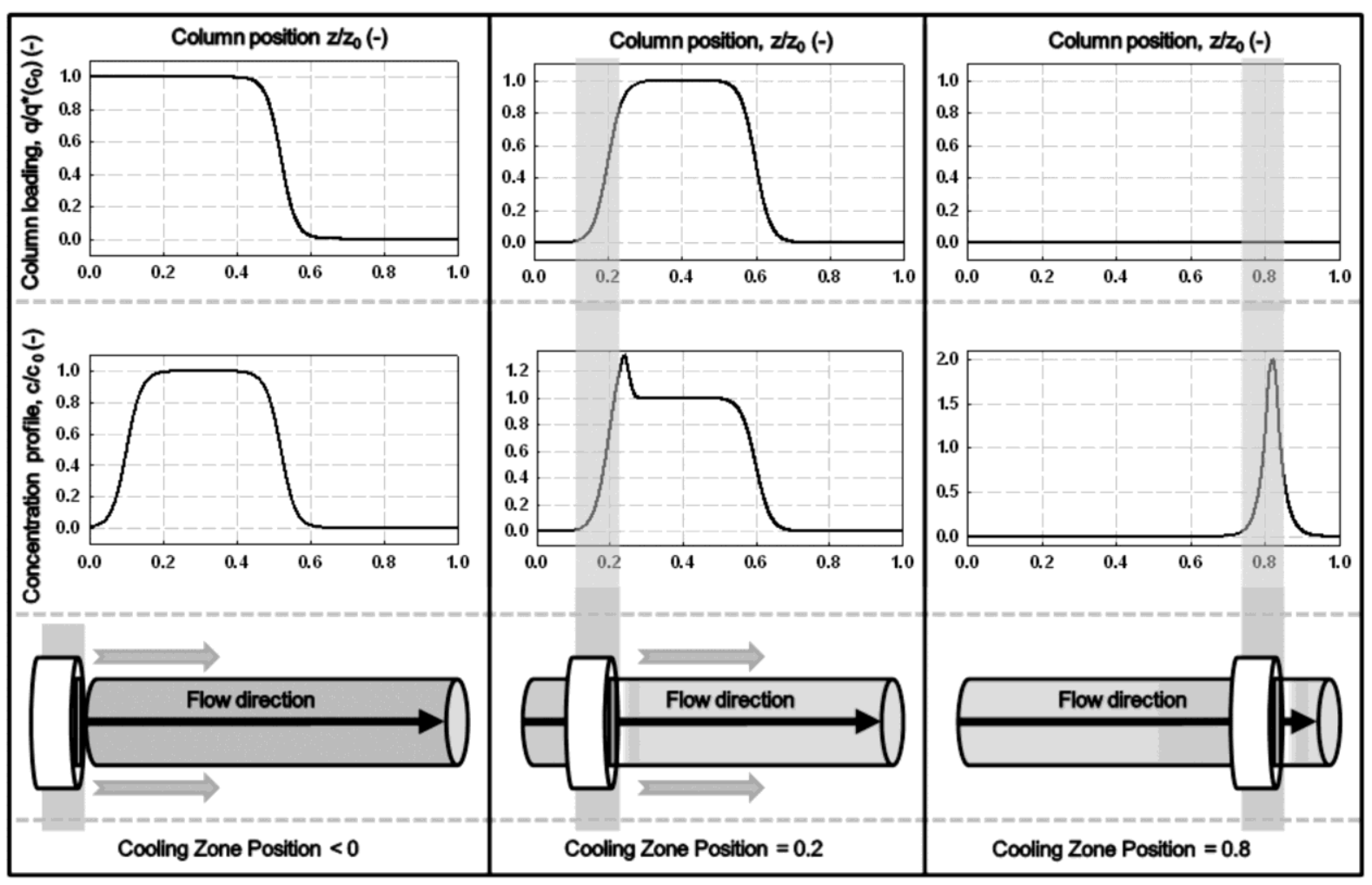

Fig. 3 


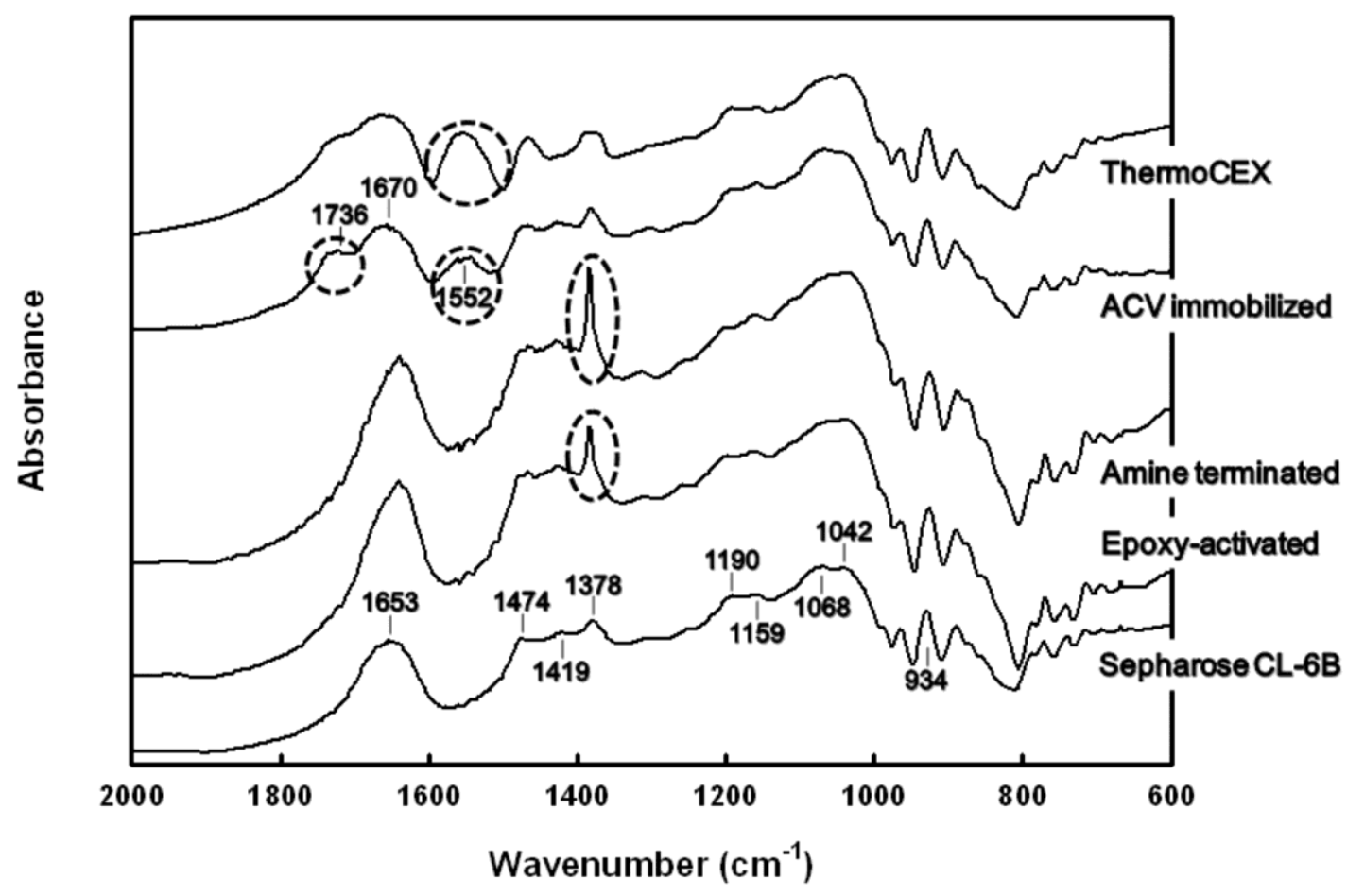

Fig. 4 


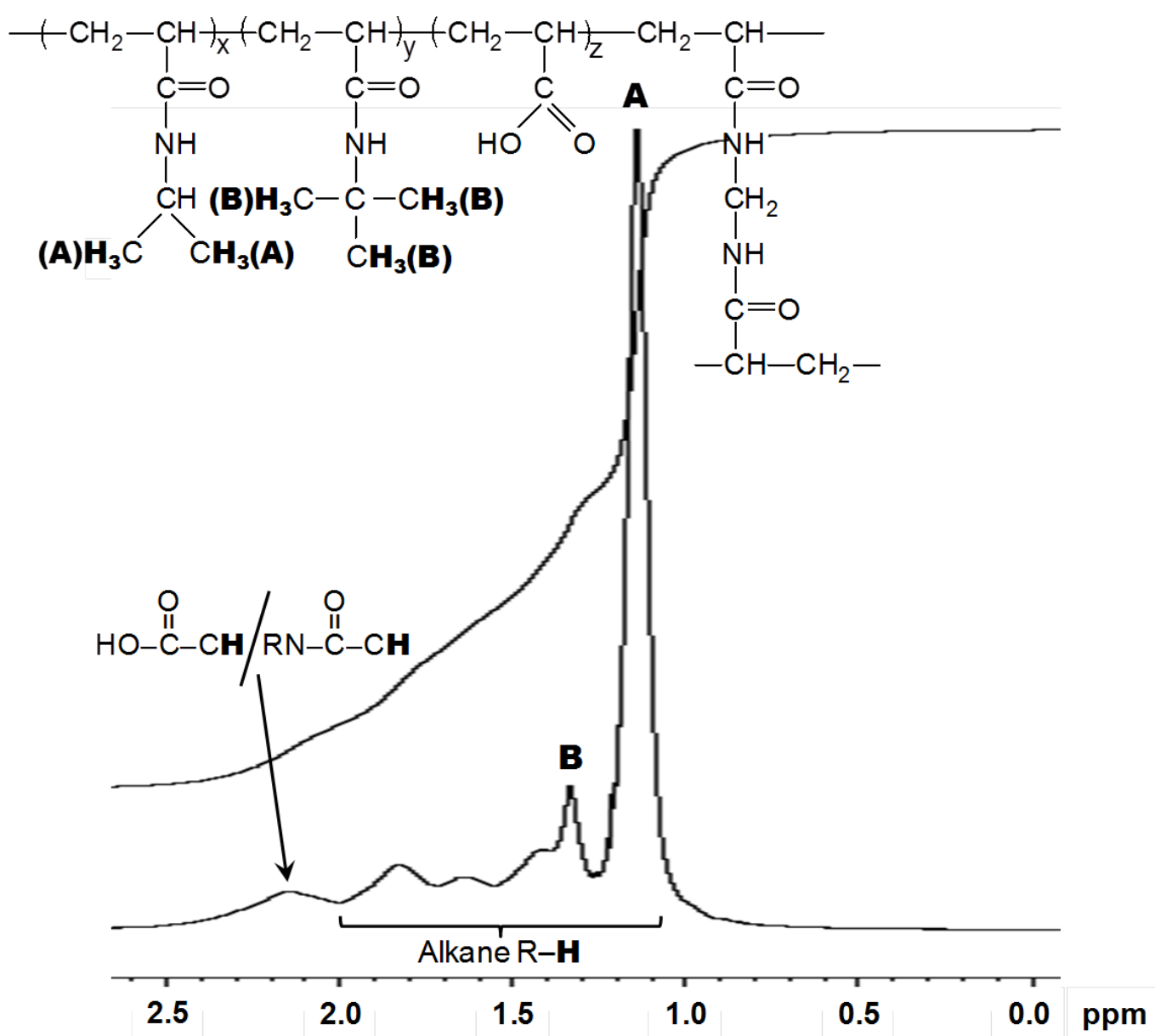

Fig. 5 


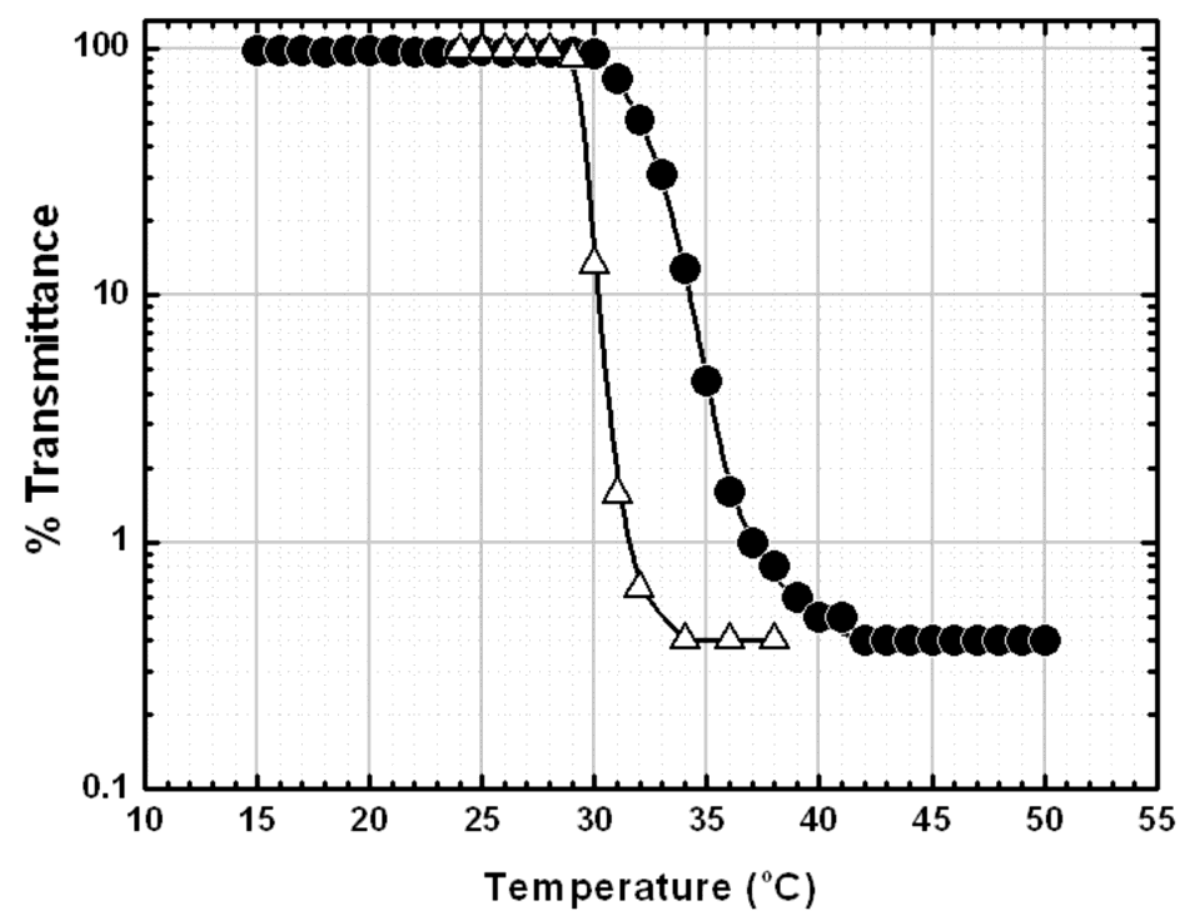

Fig. 6 

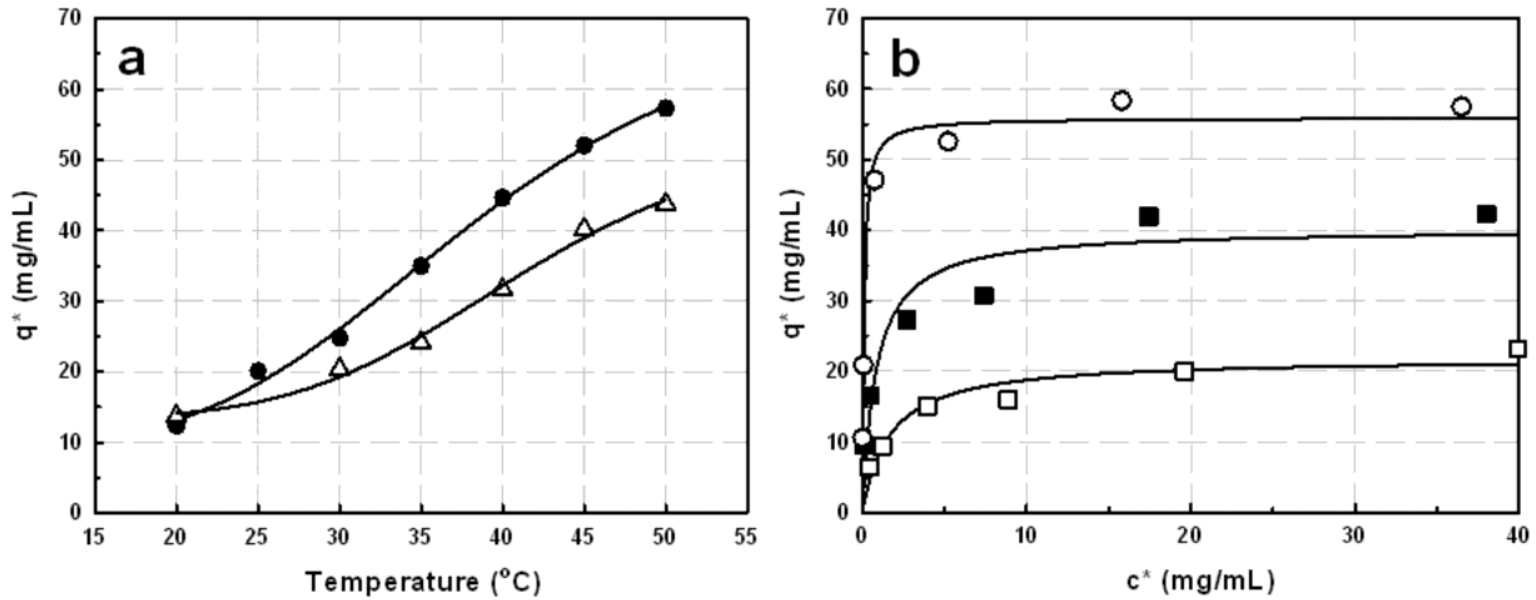

Fig. 7 

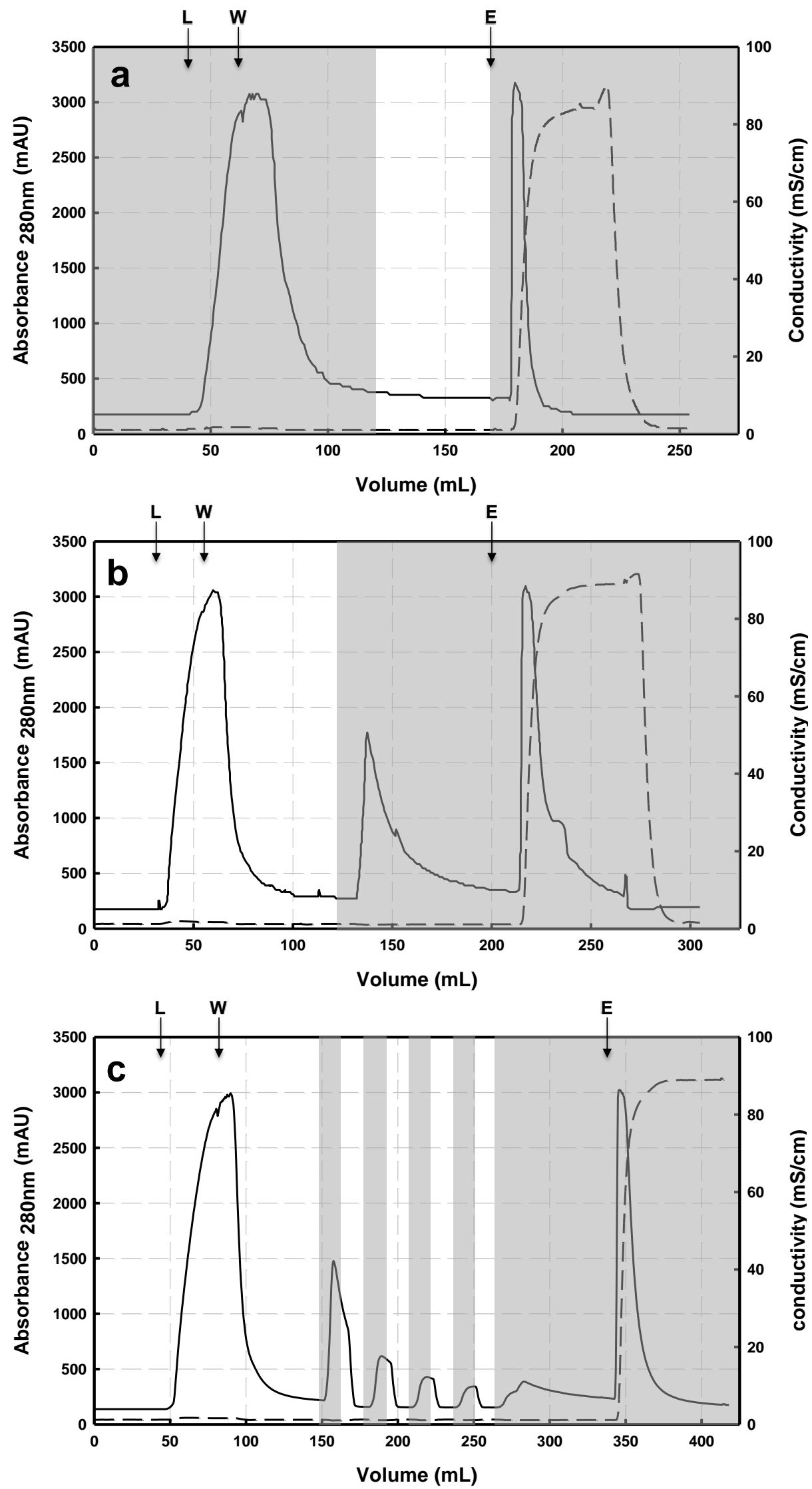

Fig. 8 


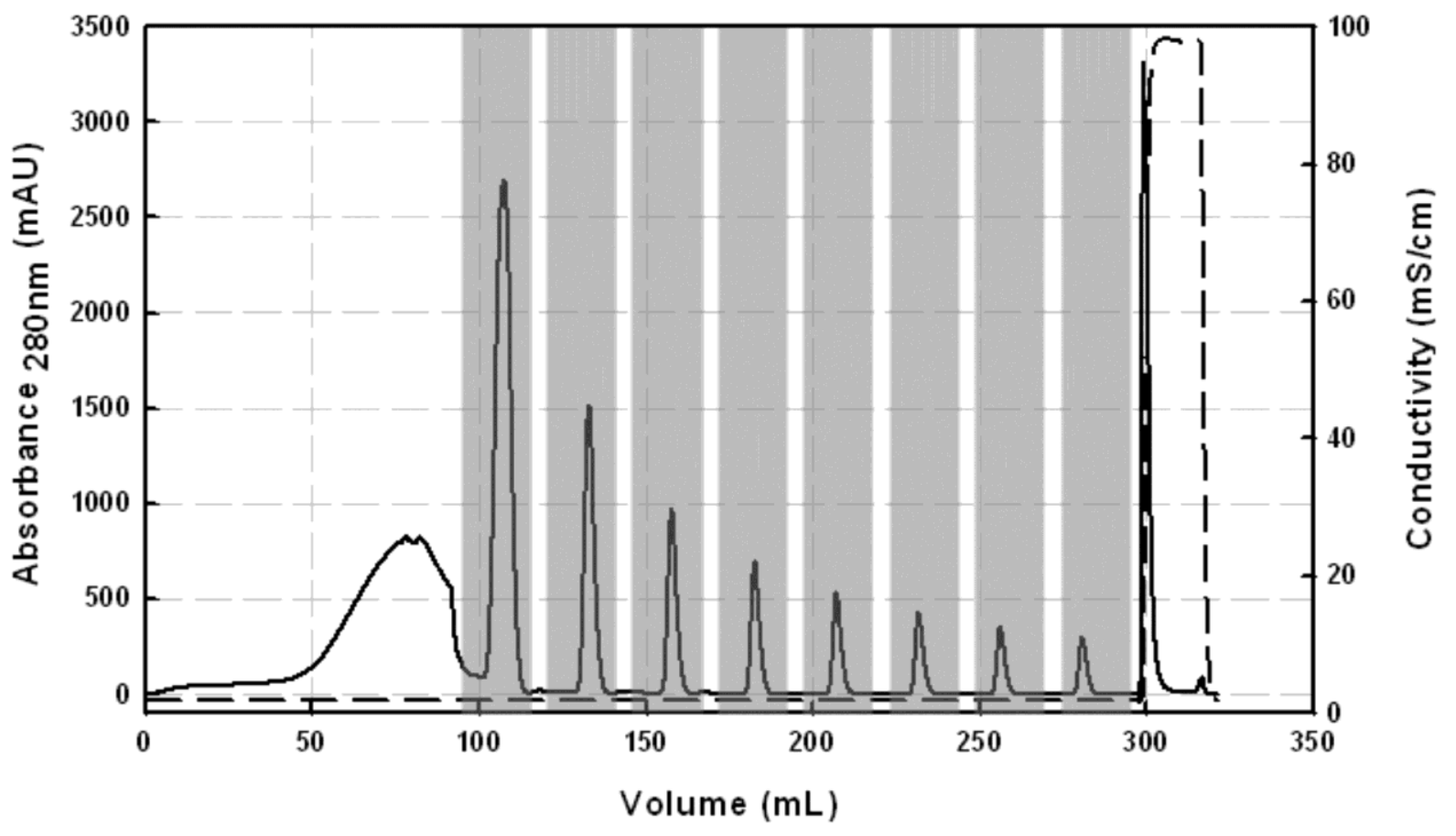

Fig. 9 


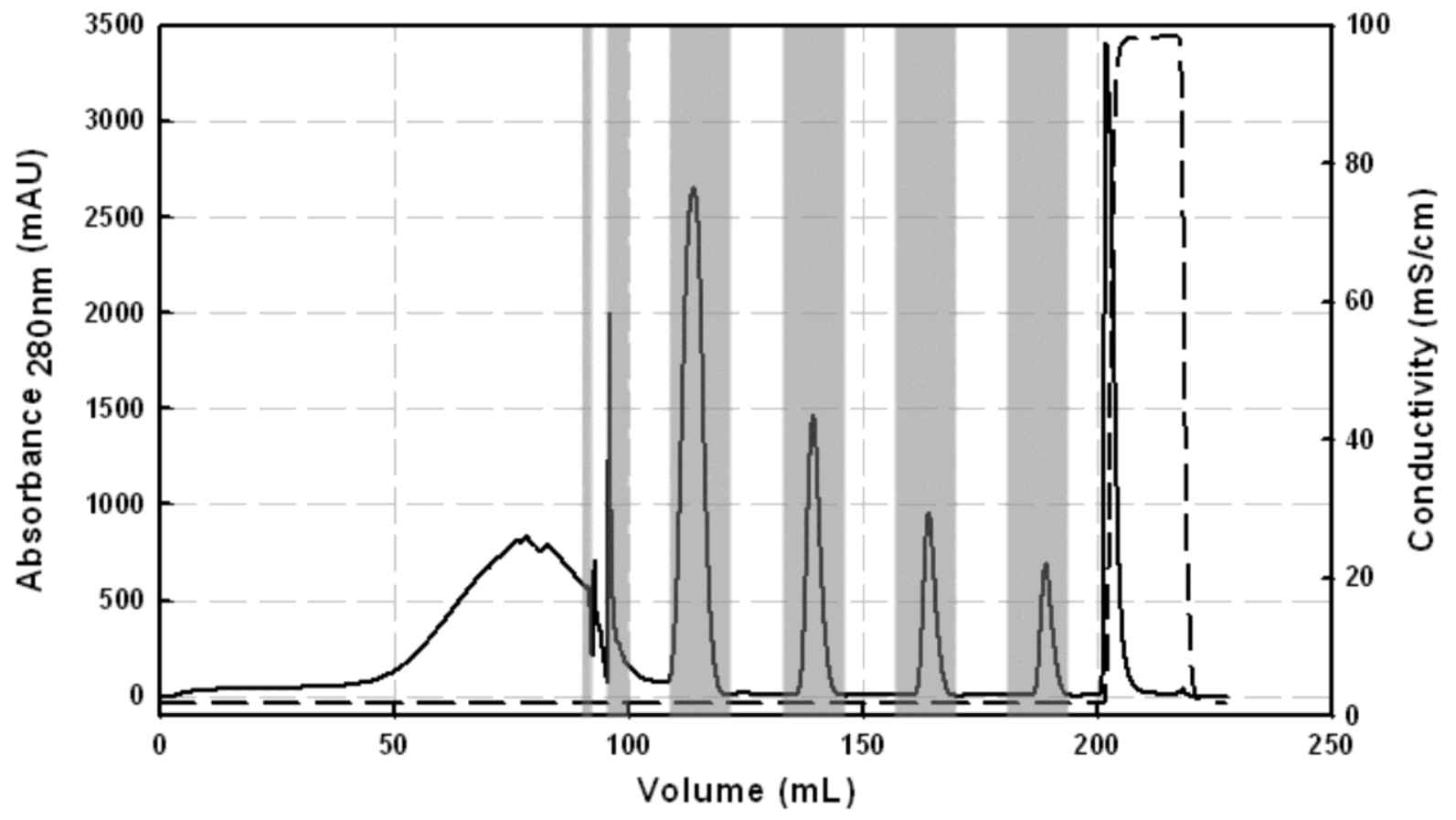

Fig. 10 